\title{
LOS PRINCIPIOS DE JUSTICIA TRIBUTARIA EN LA HISTORIA CONSTITUCIONAL CUBANA
}

\author{
THE JUSTLY TRIBUTARY PRINCIPLES \\ IN THE HISTORY CUBAN CONSTITUTIONALIST
}

\section{Liana SIMÓN OTERO*}

RESUMEN: El presente trabajo, primero, analiza, desde el punto de vista teórico, los principios de justicia tributaria y la necesidad de su regulación constitucional; posteriormente realiza un estudio histórico de la regulación de estos principios en la historia constitucional cubana, recomendando la necesidad de una reforma constitucional que legitime el actual sistema tributario.

Palabras claves: principios de justicia tributaria y Constituciones cubanas.
ABSTRACT: The present works, first, analyzes, from the theoretical viewpoint, the justly tributary principles and the need of your constitutional regulation and afterwards carries out a historical study of the regulation of these principles in the constitutional Cuban history, by recommending the need of a constitutional reform that legitimates the current tributary system.
Descriptors: justly tributary principles and cuban Constitutions.

* Profesora asistente de tiempo parcial de la Universidad de Pinar del Río. 


\section{INTRODUCCIÓN}

Con la promulgación en 1994 de la Ley 73 del Sistema Tributario, se inició en nuestro país un nuevo periodo en cuanto a la tributación, pues el cambio de política con respecto a la importancia del tributo en la recaudación de fondos públicos para la satisfacción de las necesidades sociales, fue evidente.

Este revivir del tributo en la vida económica del país trajo consigo que se revitalizaran los estudios sobre el tema, con el fin de aportar elementos teóricos que fundamenten propuestas encaminadas a democratizar y adecuar nuestro joven sistema a los requerimientos de la modernidad.

Este estudio se inserta en esa tendencia y pretende, desde la arista histórica y teórica de la regulación constitucional de los principios de justicia tributaria en Cuba, aportar una fundamentación doctrinal que de ser tomada en cuenta permita una adecuada introducción de esta materia en la carta magna cubana.

\section{LA CONSTITUCIÓN Y LOS PRINCIPIOS DE JUSTICIA TRIBUTARIA}

La incidencia del derecho constitucional en el resto de las ramas jurídicas es innegable, sin embargo en el derecho tributario cobra una notable significación.

Como bien afirma el importante tributarista español Calvo Ortega "La principal herramienta de transformación de lo que se puede llamar derecho tributario tradicional ha sido el establecimiento en las Constituciones de principios tributarios concretos". ${ }^{1}$ El derecho constitucional ha venido a contribuir directamente con la evolución hacia un sistema tributario más justo.

No es esta una posición ingenua con respecto a la justicia del sistema tributario, pues somos conscientes que resulta prácticamente imposible diseñar un sistema totalmente justo, y que por supuesto el proyecto de un sistema tributario pasa más por aspectos de orden económico y político que por la creación jurídica, pues el derecho, más que todo, es el encargado de implementar los instrumentos necesarios para el establecimiento de dicho sistema. Sin embargo, no es menos cierto que la regulación de principios tributarios constitucionales destinados a buscar mayor justicia y equidad

1 Calvo Ortega, R., "Hacia un nuevo derecho tributario", Revista Foro, Nueva época, núm. 0 , p. 61 . 
en la imposición de los tributos ha repercutido considerablemente en la eliminación de cargas tributarias excesivas, en la disminución del fraude y la evasión fiscal, y por ende en el logro de los fines del sistema y la protección del contribuyente.

Desde el punto de vista histórico resulta completamente imposible desligar la Constitución del deber de tributar, pues, como casi todos conocen, el basamento ideológico de las revoluciones burguesas y por tanto del constitucionalismo mismo, estuvo definido por las diversas nociones filosóficas y políticas que sobre el deber de contribuir se fueron conformando sobre todo en el siglo XVIII.

La regulación constitucional del deber de contribuir, desde su origen, siempre estuvo ligada al reconocimiento de un conjunto de principios básicos que orientaban la tributación.

En este sentido, mucho influyó el importante economista inglés Adam Smith complementado posteriormente por autores como Adolfo Wagner con su libro Tratado de las ciencias de las finanzas, ${ }^{2}$ Harold M. Sommers con su obra Finanzas públicas e ingreso nacional, ${ }^{3}$ y Neumark Frits con su libro Principios de la imposición. ${ }^{4}$

2 Por su parte este gran especialista alemán establece cuatro categorías de principios, los de Política Financiera, entre los que se encuentran la suficiencia de la imposición y la elasticidad o movilidad de la imposición, los de Economía Pública, refiriéndose a la elección de buenas fuentes de impuestos y la elección de las clases de impuestos, los de Equidad o de repartición equitativa de los impuestos, que implican la generalidad y la uniformidad en la tributación, y los de administración fiscal o de lógica en materia de imposición, que son la fijeza de la imposición, la comodidad de la imposición y la tendencia a reducir lo más posible los gastos de la recaudación de los impuestos. Véase Flores Zavala, Ernesto, Finanzas públicas mexicanas, México, Porrúa, 1995, pp. 149-154.

3 Para Sommers los principios fundamentales son: el principio de capacidad de pago (inspirado en el principio de justicia de Smith), el principio de beneficio, el principio de crédito por ingreso ganado, el principio de ocupación plena y el principio de conveniencia. Véase Arrioja Vizcaíno, Adolfo, Derecho fiscal, México, Themis, 2000, pp. 209 y ss.

4 Neumark establece como principios presupuestarios fiscales la suficiencia de los ingresos fiscales y la capacidad de adaptación de la imposición en la política de cobertura, como principios políticos sociales y éticos, la generalidad, la igualdad, la proporcionalidad y la redistribución social de la renta, como principios político-económicos, se refiere a los principios de ordenamiento económico, que son la evitación de medidas fiscales dirigistas, minimización de las intervenciones fiscales en la esfera privada y en la libertad económica de los individuos, y evitar las consecuencias indeseadas del impacto fiscal sobre la competencia, y los principios político-económicos propiamente dichos, que son la flexibilidad activa y pasiva de imposición y el principio de una imposición orientada hacia la política de crecimiento económico, y por último establece como principios ju- 


\section{Según Villegas,}

Adam Smith, en su obra fundamental Investigación de la naturaleza y causa de la riqueza de las naciones (1776), dejó sentadas una serie de bases relativas a la actividad financiera del Estado partiendo de premisas filosóficopolíticas que significaron una profunda trasformación en relación a las ideas entonces imperantes $(. .$.$) exponiendo una serie de principios fundamentales$ entre los cuales se hallan sus célebres reglas sobre la imposición. ${ }^{5}$

La relación/distinción norma-principio-regla es uno de los temas más debatidos en la doctrina. Atienza y Ruiz Manero afirman que "El debate como todo el mundo sabe - se inicia con un trabajo de Dworkin de 1967", ${ }^{6}$ y como podemos apreciar en la variada literatura que trata el tema, éste no se limita a los denominados principios generales del derechos, sino que se adentra en la noción de principio como categoría jurídica, y en consecuencia se refiere a su concepción, acepciones, distinción y funciones. ${ }^{7}$

Sin ánimo de pretender aportar criterios acabados o definitivos en relación con los principios, lo cual conllevaría una nueva investigación que, por

rídico tributarios y técnico-tributarios la congruencia y sistematización de las medidas fiscales, la transparencia fiscal, la factibilidad de las medidas fiscales, la continuidad del derecho fiscal, la economicidad y la comodidad de la imposición. Véase García Belaunde, Horacio A., Temas de derecho tributario, Buenos Aires, Abeledo-Perrot, pp. 67 y ss.

5 Villegas, Héctor, Curso de finanzas. Derecho financiero y tributario, Buenos Aires, Depalma, 2001, pp. 27 y 28. Los principios, que según este autor, debían regir todo el ordenamiento tributario eran el principio de justicia o proporcionalidad, el principio de certidumbre o certeza, el principio de comodidad, y el principio de economía. Véase Delgadillo, Luis Humberto, Principios de derecho tributario, México, Limusa S. A., 2007, pp. 65-68; y Arrioja Vizcaíno, Adolfo, op. cit., pp. 209 y ss.

6 Atienza, Manuel y Ruiz Manero, Juan, "Sobre principios y reglas", Revista Doxa, Madrird, núm. 10, 1991, p. 101.

7 Véase Alexy, Robert, "Sistema jurídico, principios jurídicos y razón práctica”, Revista Doxa, núm. 5, Madrid, 1988, pp. 139-151; García Canales, M., "Principios generales y Principios constitucionales", Revista de Estudios Políticos, núm. 64, 1989, pp. 131162; Atienza, Manuel y Ruiz Manero, Juan, op. cit., pp. 101-119; Peczenik, Aleksander, "Los principios jurídicos según Manuel Atienza y Juan Ruiz Manero" Revista Doxa, Madrid, núm. 12, 1992, pp. 327-331; Atienza, Manuel y Ruiz Manero, Juan, “Objeciones de principio. Respuesta a Aleksander Peczenik y Luis Prieto Sanchís”, Revista Doxa, Madird, núm. 12, 1992, pp. 333-352; Freixes Sanjuan, Teresa y Remotti Carbonel, Jose Carlos, "Los valores y principios en la interpretación constitucional", Revista Española de Derecho Constitucional, Madrid, año 12, núm. 35, 1992, pp. 97-109; y Prieto Sanchís, Luis y otros, Lecciones de teoría del derecho, Madrid, McGraw-Hill, 1997, pp. 339-357. 
supuesto, sobrepasa la presente, sí trataremos de establecer ciertas bases, a partir de las cuales deben comprenderse los principios tributarios.

Autores como Esser sostienen que el principio jurídico (aunque se refiere esencialmente a los principios generales) no es precepto ni norma "en tanto no contenga una instrucción vinculante para un determinado campo de cuestiones, sino que requiere la acuñación judicial o legislativa de dichas instrucciones"; 8 para este autor no podemos considerar que estamos en presencia de normas hasta tanto no se haya positivisado el principio, aclarando de esta forma las condiciones de su aplicación. "Larenz, tampoco parece considerarlos como normas. Para este profesor, los principios jurídicos son los pensamientos directores de una regulación jurídica determinada, ya sea existente o posible. Todavía no son normas de aplicación, pero se pueden transformar en reglas en cualquier momento". ${ }^{9}$

Siguiendo el criterio de Castro Cid sobre los principios "afirmamos (con la mayoría de la doctrina) que constituyen un tipo de normas, ya que éstas siempre orientan la acción prescribiendo o prohibiendo algo". ${ }^{10}$ Atienza y Ruiz Manero aclaran: "utilizamos los términos regla y principio como especies del género norma"."

Sobre la distinción entre principios y reglas hay dos criterios distintos bastante delimitados, y son los que defienden, por una parte, Alexy (retomando a Dworkin) y por otra, los mencionados Atienza y Ruiz Manero.

Alexy sostiene que:

El punto decisivo para la distinción entre reglas y principios es que los principios son normas que ordenan que se realice algo en la mayor medida posible, en relación con las posibilidades jurídicas y fácticas. Los principios son, por consiguiente, mandatos de optimización que se caracterizan porque pueden ser cumplidos en diversos grados y porque la medida ordenada de su cumplimiento no sólo depende de las posibilidades fácticas, sino también de las posibilidades jurídicas (...) En cambio, las reglas son normas que

8 Esser, J., Principio y norma en la elaboración jurisprudencial del derecho privado, Barcelona, Bosch, 1961, p. 69.

9 Castro Cid, Benito de, Manual de teoría del derecho, Madrid, Universitas, 2004, pp. 202 y 203.

10 Idem.

11 Atienza, Manuel y Ruiz Manero, Juan, “Sobre principios y reglas”, cit., p. 102. 
exigen un cumplimiento pleno y, en esa medida, pueden siempre se sólo o cumplidas o incumplidas. ${ }^{12}$

Atienza y Ruiz Manero critican esta concepción, teniendo en cuenta que hay principios en sentido estricto a los cuales no se les puede aplicar esta teoría, porque su cumplimiento no puede producirse en diversos grados, sino que se cumple o no.

La diferencia [según estos autores] estriba en que los principios configuran el caso de forma abierta, mientras que las reglas lo hacen de forma cerrada. Con ello queremos decir que mientras que en las reglas las propiedades que conforman el caso constituyen un conjunto cerrado, en los principios no puede formularse una lista cerrada de las mismas: no se trata sólo de que las propiedades que constituyen las condiciones de aplicación tengan una periferia mayor o menor de vaguedad, sino de que tales condiciones no se encuentran siquiera genéricamente determinadas. ${ }^{13}$

La esencia del debate entre estos autores se ha centrado en la determinación del elemento que constituye el punto a partir del cual se diferencian los principios y las reglas. Aun cuando partimos de considerar que los dos criterios no son excluyentes, ni errados, sí reconocemos que la distinción establecida por Atienza y Ruiz Manero es determinante, pues el criterio de distinción del que parte Alexy puede tender a confusión cuando analizamos determinados principios.

Esta aparente contradicción nos permite afirmar que los principios son normas que carecen de hipótesis jurídica, es decir, las circunstancias que deben darse para su aplicación a un caso concreto no están delimitadas en un marco cerrado de condiciones, todo lo contrario a lo que ocurre con las reglas. También podemos decir que se trata de normas que pueden ser cumplidas en diversos grados, pues el hecho de que determinados principios permitan su completo cumplimiento (máximo grado de cumplimiento), no significa que, en sentido general, este mandato de optimización no los defina.

El problema del criterio defendido por Alexy en relación a los principios que, relativamente fácil, permiten un cumplimiento pleno, estriba en que no nos ofrece claridad para distinguirlos de las reglas, las que sí van a ser

12 Alexy, Robert, op. cit., pp. 143 y 144.

13 Atienza, Manuel y Ruiz Manero, Juan, op. cit., pp. 108. 
o cumplidas o no cumplidas, siempre. Por lo que podría crearse confusión si asumimos este criterio como punto de distinción.

No todos los autores asumen esta distinción entre principios y reglas, así Rodríguez Bereijo manifiesta que los principios: "Son reglas o preceptos normativos que presuponen la existencia de otras normas específicas; su objeto consiste no tanto en regular relaciones o definir posiciones jurídicas concretas cuanto en versar sobre la aplicación de las normas", ${ }^{14} \mathrm{y}$ siguiendo el criterio de García de Enterría ${ }^{15}$ argumenta que son "normas sin presupuesto de hecho concreto, en cuanto son «una mezcla de precisión (que evita su disolución nebulosa) e indeterminación (que permite su dinamicidad y su superior grado para dominar supuestos muy varios)» (...), sin llegar por sí mismas a suministrar decisiones a los casos concretos". ${ }^{16}$

Si bien para Alexy, Atienza y Ruiz Manero está muy clara la diferencia entre principio y regla, Rodríguez Bereijo, por su parte, equipara los dos términos y define a los principios precisamente como reglas generales, no atribuyéndoles un carácter totalmente indeterminado como Atienza y Ruiz Manero, sino que les reconoce cierto grado de precisión. Esta concepción limita la función de los principios dentro del ordenamiento jurídico, pues los circunscribe simplemente a criterios relacionados con la interpretación jurídica, pero que por sí mismos no pueden resolver un caso concreto.

Siguiendo el criterio de García Canales:

...los principios constitucionales forman un conjunto homogeneizado por el dato capital de su supremo valor normativo dentro del ordenamiento jurídico. Sean principios constitucionalizados, sean principios inducidos del articulado constitucional, los principios constitucionales participan de la fuerza normativa de la Constitución en relación con las restantes normas del ordenamiento. ${ }^{17}$

14 Rodríguez Bereijo, Álvaro, "El sistema tributario en la Constitución”, Revista Española de Derecho Constitucional, Madird, año 12, núm. 36, septiembre-diciembre de 1992, p. 22.

15 Véase García de Enterría, Eduardo y Fernández Rodríguez, Tomás Ramón, Curso de derecho administrativo, 5a. ed.,1, Madrid, Civitas, 1991, t. I, pp.

16 Rodríguez Bereijo, Álvaro, op. cit., p.22.

17 García Canales, M., "Principios generales y Principios constitucionales", Revista de Estudios Políticos (Nueva Época), núm. 64, 1989, p. 149. 
Los principios recogidos en el texto constitucional son aquellos que por su importancia, ya sea para la conformación del sistema económico, político y jurídico, para la relación Estado-individuo, o para una materia en particular, son elevados al más alto rango dentro de la pirámide normativa. Pero, ¿cómo identificamos los principios en el texto constitucional? La propia Constitución de manera expresa formula un conjunto de principios y le da, por su propia denominación, el carácter de tales; no obstante pueden existir en el propio texto otro conjunto de preceptos que aunque no reciban tal denominación, mediante la interpretación puede entenderse que se trata de principios.

Es en estos casos que se nos presenta el problema de considerarlos o no como principios, pues evidentemente corresponderá, o la autoridad facultada para realizar la interpretación, o en general a los operadores jurídicos, particularmente a los jueces, decidir discrecionalmente si estamos en presencia o no de un principio constitucional.

En correspondencia, los principios de justicia tributaria son normas tributarias de rango constitucional que carecen de hipótesis jurídica, que constituyen criterios para enjuiciar el sistema tributario y sus componentes, que sirven de protección al contribuyente y que deben ser cumplidos en el mayor grado posible, tanto por el legislador, como por los operadores jurídicos.

Calvo Ortega sostiene que:

Se trata de preceptos permanentes (como todo principio), lo que supone que no se agotan con su aplicación. Son generales, es decir, se extienden a todos los tributos, [y] son directamente aplicables a situaciones y relaciones jurídicas muy diversas. No estamos, pues, ante normas programáticas que sirven de quía al legislador, sino de preceptos que pueden ser invocados directamente ante un Tribunal Constitucional que constituye la garantía de su observancia o alegados ante un tribunal ordinario. ${ }^{18}$

Desde este punto de vista los principios constitucionales tributarios no sólo informan u orientan al resto del ordenamiento jurídico tributario, con vistas a lograr un sistema tributario más justo, sino que por sí mismos pueden ser aplicados a un caso concreto por un tribunal de justicia y solucionar así, con mayor equidad, un asunto jurídico. 


\section{LOS PRINCIPIOS DE JUSTICIA TRIBUTARIA:}

\section{PRINCIPIOS DE JUSTICIA FORMAL Y PRINCIPIOS DE JUSTICIA MATERIAL}

Teniendo en cuenta el ámbito de aplicación de los principios tributarios la doctrina los ha clasificado en principios de justicia material y principios de justicia formal.

Martín Queralt, Lozano Serrano y Poveda Blanco sostienen: "Reflejado el valor esencial que tienen los principios constitucionales en el ordenamiento tributario, conviene analizar cada uno de ellos, distinguiendo entre principios materiales (...) y principios formales". ${ }^{19}$

Así también lo hace Rodríguez Bereijo cuando trata de manera separada los principios formales de la imposición de los principios materiales o de justicia de la imposición. ${ }^{20}$

Según los mencionados Martín Queralt, Lozano Serrano y Poveda Blanco, los principios materiales son aquellos "que alertan sobre el contenido sustantivo que debe tener una determinada materia". ${ }^{21}$ Es por eso, que su máximo valor está en que sean realmente aplicados como criterios de justicia, y respetados al momento de la concepción de los tributos; pues todos se interrelacionan, no pudiendo subsistir unos sin la presencia de los otros.

Los principios materiales habitualmente reconocidos son: la capacidad contributiva, la generalidad, y la progresividad y no confiscatoriedad del tributo, y, en algunos casos, el principio de justicia en el gasto público.

Pérez Royo, al comentar el artículo 31 de la Constitución Española de 1978, sostiene: "En los tres apartados de este fundamental precepto se condensan los principios o criterios materiales sobre el reparto de la carga tributaria (principios de capacidad económica, de generalidad, de igualdad, de progresividad, de no confiscación)". ${ }^{22}$ Mientras que Villegas plantea: "A su vez, la capacidad contributiva es la base fundamental de donde parten las garantías materiales que la Constitución otorga a los

19 Martín Queralt, Juan, Lozano Serrano, Carmelo, Poveda Blanco, Francisco, Derecho tributario, 13a. ed., Navarra, Thomson Arazandi, 2008, p. 53.

20 Véase Rodríguez Bereijo, Álvaro, op. cit., pp. 26 y 39.

21 Martín Queralt, Juan, Lozano Serrano, Carmelo, Poveda Blanco, Francisco, op. cit., p. 53.

${ }^{22}$ Pérez Royo, Fernando, Derecho financiero y tributario. Parte General, Navarra, Arazandi, 2005, p. 53. 
habitantes, tales como la generalidad, igualdad, proporcionalidad y no confiscatoriedad". ${ }^{23}$

Siguiendo esta última tendencia, que incluye a la igualdad como principio material, están también Martín Queralt, Lozano Serrano y Poveda Blanco, al manifestar: "De entre los principios materiales hay que prestar especial atención a los principios de generalidad, igualdad, progresividad, no confiscatoriedad y capacidad económica". ${ }^{24}$

Por su parte, los principios tributarios de justicia formal son aquellos que atienden a los requisitos de estructuración de las normas jurídicas que forman parte del sistema tributario, son los principios "que se limitan a establecer los cauces formales que debe seguir la regulación de la materia en cuestión", ${ }^{25} \mathrm{O}$ como afirma Villegas son "sólo una garantía formal de competencia en cuanto al órgano productor de la norma". ${ }^{26} \mathrm{~A}$ diferencia de los materiales, los principios de justicia formal, se refieren más a criterios de forma que de contenido.

La doctrina comúnmente reconoce al principio de reserva de ley y/o al principio de legalidad. ${ }^{27}$

Martín Queralt, Lozano Serrano y Poveda Blanco afirman: “El principio formal por excelencia es el principio de reserva de ley", mientras que Pérez Royo defiende que:

La primera de estas reglas [formales] sobre la producción normativa en materia tributaria es la del principio de legalidad tributaria, que aparece como la clave de bóveda del edificio de fuentes del derecho en este ámbito (...) Se habla, en este sentido, de reserva de ley, aunque por nuestra parte preferimos

23 Villegas, Héctor B., Curso de finanzas. Derecho financiero y tributario, Buenos Aires, Depalma, 2001, p. 199.

${ }^{24}$ Martín Queralt, Juan, Lozano Serrano, Carmelo, Poveda Blanco, Francisco, op. cit., p. 54.

25 Ibidem, p. 53.

26 Villegas, Héctor B., op. cit., p. 187.

27 El principio de validez en el ordenamiento interno de los tratados internacionales debidamente suscritos por el Estado, también es considerado, por algunos autores, como un principio tributario de justicia formal. A pesar, de que su incidencia es clara en el ámbito tributario, también lo es en cualquier otra materia, sobre todo de derecho público. Por tanto, considerando que se trata de un principio más vinculado al derecho internacional y constitucional, que al tributario, hemos decidido no tratarlo en este marco. Véase Martín Queralt, Juan; Lozano Serrano, Carmelo; Casado Ollero, Gabriel y Tejerizo López, José Manuel, Curso de derecho financiero y tributario, La Habana, Félix Varela, 2006, pp. 164-169. 
la denominación de principio de legalidad (...) No obstante, en el lenguaje actual ambas expresiones se usan como sinónimos. ${ }^{28}$

Ese mismo criterio es seguido por la mayoría de los tributaristas. Rodríguez Bereijo establece como principios formales de la imposición "el principio de legalidad tributaria o de reserva de ley", ${ }^{29}$ Zavala Ortiz se refiere: "el principio de legalidad denominado reserva legal..." ${ }^{30}$ y García Vizcaíno, también equiparándolos, se expresa en esos mismos términos “... el principio de legalidad o reserva en materia tributaria...". ${ }^{31}$

A pesar de este aparente consenso doctrinal, y siguiendo el criterio que distingue estos principios, asumiremos su tratamiento de manera conjunta, pero independiente, partiendo de que, aunque guardan una estrecha relación, no son absolutamente coincidentes.

\section{EL PRINCIPIO DE CAPACIDAD CONTRIBUTIVA}

Son varios los autores que equiparan la capacidad económica a la capacidad contributiva. Ferreiro Lapatza sostiene: "Capacidad contributiva es igual a capacidad económica. Es igual a capacidad para contribuir, para soportar las cargas económicas derivadas de los tributos". ${ }^{32}$ Por su parte, Calvo Ortega, en ese mismo sentido, concibe la capacidad económica como "la aptitud, (...) la posibilidad real, (...) la suficiencia de un sujeto de derecho para hacer frente a la exigencia de una obligación dineraria concreta por parte de una administración pública". ${ }^{33}$

No obstante, como bien afirma Francesco Moschetti: "si bien es cierto que no puede haber capacidad contributiva en ausencia de capacidad económica, también es cierto que pueden existir capacidades económicas no demostrativas de aptitud para la contribución". ${ }^{34}$ De ahí que debamos

28 Pérez Royo, Fernando, op. cit., pp. 61 y 62.

29 Rodríguez Bereijo, Álvaro, op. cit., p. 26.

30 Zavala Ortiz, José Luis, Manual de derecho tributario, Santiago de Chile, ConoSur Ltda., p. 16.

31 García Vizcaíno, Catalina, op. cit., p. 272.

32 Ferreiro Lapatza, José Juan, Curso de derecho financiero español, Madrid, Marcial Pons, 1994, p. 388.

33 Calvo Ortega, Rafael, op. cit., p. 69.

34 Moschetti, Francesco, El principio de capacidad contributiva, Madrid, Instituto de Estudios Fiscales, 1980, p. 276. 
diferenciar dos conceptos que, aunque muy relacionados, se refieren a realidades diferentes.

La capacidad económica está determinada por el valor del patrimonio de cada persona, por el capital que posea cada sujeto; mientras que "la capacidad contributiva viene dada por aquella parte de la potencia económica, (...) que supera el mínimo vital. En efecto, si “capacidad" significa aptitud, posibilidad concreta y real, no puede existir capacidad de concurrir a los gastos públicos cuando falte o se tenga sólo lo necesario para las exigencias habituales". ${ }^{35}$

Toda persona tiene determinada capacidad económica, más o menos restringida, en dependencia de la situación económica del país donde resida $\mathrm{y}$ de los ingresos que perciba en función de sus gastos. Esto no significa que la manifestación de esa capacidad sea suficiente para convertirse en un potencial contribuyente, pues puede suceder que esa persona ni siquiera pueda satisfacer sus necesidades elementales, con lo cual sería totalmente injusto someterlo a gravamen.

Tal como asevera Moschetti: "Capacidad contributiva no es, por tanto, toda manifestación de riqueza, sino sólo aquella potencia económica que debe juzgarse idónea para concurrir a los gastos públicos, a la luz de fundamentales exigencias económicas y sociales", ${ }^{36} \mathrm{o}$, como afirma Valdés Costa, las "facultades económicas del contribuyente, es decir, la posibilidad económica que tiene el individuo de contribuir a sufragar los gastos públicos destinados a satisfacer las necesidades colectivas". ${ }^{37}$ Villegas, siguiendo esta misma línea doctrinal, sostiene:

En cuanto al concepto de capacidad contributiva, nos parece correcto el de Fernando Sainz de Bujanda, según quien la capacidad contributiva supone en el sujeto tributario la titularidad de un patrimonio o de una renta, aptos en cantidad y en calidad para hacer frente al pago del impuesto, una vez cubiertos los gastos vitales e ineludibles del sujeto. ${ }^{38}$

35 Calvo Ortega, Rafael, op. cit., p. 68.

36 Moschetti, Francesco, op. cit., p. 277.

37 Valdés Costa, Ramón, Instituciones de derecho tributario, Buenos Aires, Depalma, 1992, p. 445.

38 Villegas, Héctor B., op. cit., pp. 198 y 199. 
La capacidad contributiva se nos manifiesta entonces no sólo desde el punto de vista objetivo, como capital, sino también desde el punto de vista subjetivo, en relación con la persona del contribuyente.

Desde el punto de vista subjetivo la determinación de la capacidad contributiva depende de la cuantificación de la llamada exención del mínimo vital, la cual fue proclamada por la doctrina alemana y consiste en que una determinada cantidad no puede ser gravada por estar destinada a la satisfacción de las necesidades vitales de su titular.

Según Roa "El alemán Helferich justifica la exención del mínimum de subsistencia, diciendo que se considera que las personas así exceptuadas, prestan al Estado un servicio material equivalente al montante del impuesto"; 39 mientras que:

En Ricardo encontramos desde el punto de vista económico, los primeros elementos que pueden servir para su justificación. Él sostenía que la facultad de pago debía apreciarse según la renta neta, que es la que resulta de la deducción de los gastos de producción. Después de deducidos estos gastos directos, entonces tiene la persona la facultad o habilidad para pagar el impuesto, y si deducidos los gastos de producción — manutención, vestido, vivienda, etcétera - no queda ninguna renta porque todo se ha consumido, no debe pagarse el impuesto. ${ }^{40}$

Por la propia concepción de la exención del mínimo vital, resulta imposible definir o establecer un mínimo estándar, que se adecue a todas las sociedades y a todos los tiempos, porque sería tanto como afirmar que todas las personas conviven con igual situación económica, lo cual pudiera ser deseable, pero desafortunadamente resulta irreal.

Como bien afirma Martín Delgado,

la dimensión de este mínimo de existencia va a depender en concreto de cómo esté configurado el sistema financiero del Estado y de cuáles sean las actividades que se desarrollan por el mismo. Es evidente que un Estado en que las primeras necesidades de los individuos aparezcan cubiertas por la actividad pública, es decir, por la actuación del sector público, la exención del mínimo de existencia tendrá menos sentido que en aquellos Estados en

39 Roa, Arsenio, Ensayo de hacienda pública, La Habana, Imprenta y Papelería de Rambla, Bouza y Ca., 1927, p. 239.

${ }^{40}$ Ibidem, p. 240. 
los que el fundamento liberal de la organización socioeconómica deje al libre juego de las economías individuales la cobertura de estas necesidades. ${ }^{41}$

En consecuencia, podemos establecer tres requisitos básicos que deben tenerse en cuenta al momento de establecer cuál es el mínimo vital:

- El costo de la vida.

- El nivel de desarrollo económico que haya alcanzado el país.

- Los servicios públicos que gratuitamente brinde el Estado.

Desde el punto de vista objetivo, tal y como afirma Rodolfo Spisso, ${ }^{42}$ la capacidad contributiva requiere la presencia de tres requerimientos:

- Que el tributo recaiga sobre la riqueza disponible, sobre rendimientos netos.

- Que no exista separación entre los distintos periodos impositivos, para que no se distorsione la capacidad contributiva.

- Que se grave la riqueza real, objetiva, sin que se establezcan presunciones iure et de iure sobre una riqueza sólo probable.

Los criterios doctrinales sobre la función, configuración y concepción de este principio son muchos. Pérez de Ayala ${ }^{43}$ concibe al principio de capacidad contributiva como un prerrequisito para el establecimiento del resto de los principios, como la base común que sostiene a la progresividad, la igualdad o la no confiscatoriedad. Desde este punto de vista no se puede establecer ninguna carga tributaria si no existe una previa manifestación de capacidad contributiva.

Calvo Ortega ${ }^{44}$ lo considera la razón de ser de la imposición, la causa que justifica el hecho de contribuir; mientras que Gamba Valega ${ }^{45}$ sostiene que

41 Martín Delgado, Jaime, "Los principios de capacidad económica e igualdad en la Constitución Española de 1978”, Hacienda Pública Española, Madrid, núm. 60, 1979, p. 66.

42 Véase Spisso, Rodolfo, Derecho constitucional tributario, Buenos Aires, Depalma, 2003 , pp. 361 y 362.

43 Véase Pérez de Ayala, José Luis, "Las cargas públicas: principios constitucionales para su distribución”, Hacienda Pública Española, Madrid, núm. 59, 1979, pp. 87 y ss.

44 Véase Calvo Ortega, Rafael, op. cit.

45 Véase Gamba Valega, César, Regímenes especiales del IGV y principios tributarios, en www.ipdt.org/editor/docs/Gamba13-07-05.pdf. 
la capacidad contributiva es la medida de la contribución de cada persona que posee el deber de tributar.

Domínguez de Oliveira resume estos dos criterios cuando afirma:

...La capacidad contributiva es un concepto que se comprende en dos sentidos, uno objetivo o absoluto y otro subjetivo o relativo. En el primer caso, la capacidad contributiva significa la existencia de una riqueza sobre la cual se tributa (capacidad contributiva como supuesto de tributación) mientras tanto en el segundo, una parte de esa riqueza será objeto de tributación en función a las condiciones individuales (capacidad contributiva como criterio de graduación y límite del tributo). ${ }^{46}$

La capacidad contributiva absoluta es la que fundamenta el hecho de contribuir y por tanto el cumplimiento del deber constitucional, pues se debe porque se tiene capacidad contributiva para soportar el tributo; mientras que la capacidad contributiva relativa es la medida, la proporción de cada contribución del sujeto, pues se debe según la capacidad que se tenga. Es por esto que en la práctica sólo podemos exigir la capacidad contributiva relativa, teniendo en cuenta que la pretensión tiene que ser proporcional, lo que no impide que en la configuración formal del tributo se deba tener en cuenta la capacidad contributiva absoluta.

En este sentido resulta significativa la definición de los hechos que son indicativos de capacidad contributiva. Giardina ${ }^{47}$ formuló el llamado principio de normalidad, según el cual el legislador, cuando configura una determinada situación como hecho imponible está atendiendo a un supuesto que "debe ser" o que "normalmente" es indicativo de esa capacidad contributiva, pero esto no significa que realmente sea así en todos los casos. La ley, por su carácter general, no puede diferenciar en un mismo hecho qué supuestos manifiestan capacidades económicas y cuáles no; de ahí que la solución a éste problema deba ofrecerse por la vía de las bonificaciones y exenciones.

Lo que sí debe quedar claro es que el principio de capacidad contributiva se encuentra inevitablemente unido a los demás principios de justicia tributaria, y debe ser considerado desde una perspectiva amplia, pues es el

46 Domínguez de Oliveira, José Marcos, Capacidade contributiva. Conteúdo e eficacia do principio, Río de janeiro, Renovar, 1988, p. 36.

47 Véase Giardina, Emilio, Le basi teoriche del principio della capacita contributiva, Milán, Giuffré,1961. 
ordenamiento tributario, visto integralmente, el que debe ser indicativo de la capacidad contributiva.

\section{EL PRINCIPIO DE GENERALIDAD TRIBUTARIA}

Algunos autores no le otorgan independencia, sino que lo asumen como una manifestación de la igualdad ante la ley, ${ }^{48} \mathrm{o}$ lo limitan en su concepción.

Figueroa Valdés, por ejemplo, sostiene que, en virtud de la generalidad "la ley tributaria ha de tener aplicación sobre todos los contribuyentes que se encuentren en las circunstancias contempladas por el legislador al establecer la regla de derecho, de modo tal que los impuestos los paguen todos aquellos que están en la situación objetiva contemplada en la ley". ${ }^{49}$

Desde esta posición se limita el principio de generalidad al instante de la aplicación de las normas tributarias, cuando este principio se refiere fundamentalmente al momento de creación de la ley, para que ésta contemple todos los supuestos de manifestación de riqueza que sean indicativos de capacidad contributiva. En otras palabras, la ley debe comprender de manera abstracta e impersonal a todas las personas que realicen el hecho imponible.

Villegas, amparando la no independencia de este principio, sostiene:

...un escritor tan prestigioso como el español Pérez de Ayala llega a decir -refiriéndose a la generalidad (a la que llama "universalidad") y a la igualdad- que esos principios no pueden considerarse criterios de realización de justicia tributaria, sino reglas de aplicación y desarrollo del principio de capacidad económica. ${ }^{50}$

Con lo cual, evidentemente, le está restando autonomía, para subsumirlo dentro del principio, que él denomina, de capacidad económica.

Un gran sector de la doctrina, ${ }^{51}$ podríamos decir que mayoritario, considera que el principio de generalidad, aún cuando guarda una estrecha

48 Véase Massone Parodi, Pedro, Principios de derecho tributario, Valparaíso, EDEVAL, 1979, passim, y Lara Berríos, Bernardo, "Derechos y garantías de los contribuyentes en Chile", Revista del Centro de Servicio de Impuestos Internos, 2002, passim.

49 Figueroa Valdés, Juan Eduardo, Las garantías constitucionales del contribuyente en la Constitución Politica de 1980, Editorial Jurídica de Chile, 1985, p.185.

50 Villegas, Héctor B., op. cit., p. 199.

51 Véase Saccone, Mario Augusto, Manual de derecho tributario, Buenos Aires, La Ley, 2002, p.70; Pérez Royo, Fernando, op. cit., pp. 58 y 59; Calvo Ortega, Rafael, op. 
relación con otros principios, como el de igualdad o capacidad contributiva, mantiene una total autonomía; pues se distingue esencialmente por su marcado carácter subjetivo. Si bien el principio de capacidad contributiva se refiere a quiénes pagan el tributo, la generalidad establece cómo se grava. El principio de generalidad resulta mucho más abstracto porque responde al deber general que tienen todos de tributar.

Visto de este modo dicho principio, según Martín Queralt, Lozano Serrano, Casado Ollero y Tejerizo López: "constituye un requerimiento directamente dirigido al legislador para que cumpla con una exigencia: tipificar como hecho imponible todo acto, hecho o negocio jurídico que sea indicativo de capacidad económica". ${ }^{52}$ Es decir, todas las personas están sujetas a la tributación, sin que puedan establecerse exoneraciones estrictamente subjetivas, según este principio todo el que manifieste capacidad contributiva está en la obligación de tributar, sea persona natural o persona colectiva o moral, no puede haber distinción de sexo, edad nacionalidad, etcétera

Desde este mismo punto de vista, un colectivo de autores cubanos afirma: "El criterio de generalidad parte de que todas las personas jurídicas o naturales, en tanto tengan capacidad de contribuir, deben estar sometidas a la imposición, ya que todos son beneficiarios de la actividad del Estado". ${ }^{33}$

Bien sostiene Calvo Ortega: "El principio es, por una parte, una reacción contra privilegios históricos que declaraban exentas a personas y clases determinadas y, por otro lado, una manifestación concreta del más amplio de igualdad ante la ley; en nuestro caso ante la ley fiscal". ${ }^{54}$

Aunque pueda parecer que resulta imposible establecer exenciones y bonificaciones, no son exactamente todas las exenciones y bonificaciones las que quedan prohibidas en virtud de este principio, sino sólo aquellas que resultan discriminatorias, en virtud de que no se pueden tratar de manera diferente situaciones que son equivalentes sin una justificación razonable, sin que estén respaldadas por el propio ordenamiento jurídico y más exactamente por la propia Constitución.

cit., p. 68; Martín Queralt, Juan, Lozano Serrano, Carmelo, Poveda Blanco, Francisco, op. cit., p. 54; y Rodríguez Bereijo, Álvaro, op. cit., pp. 40 y 41

52 Martín Queralt, Juan; Lozano Serrano, Carmelo; Casado Ollero, Gabriel y Tejerizo López, José Manuel, op. cit., p. 148.

53 Administración financiera del Estado cubano, La Habana, Centro de estudios Contables, Financieros y de Seguros, 2005, p. 234.

${ }^{54}$ Calvo Ortega, Rafael, op. cit., p. 68. 
La regulación de exoneraciones tiene que estar determinada por un fundamento constitucional, y basada en determinadas manifestaciones de capacidad contributiva. Es por esto que hoy en día podemos establecer determinas exenciones y bonificaciones teniendo en cuenta fines extrafiscales o de política económica, pues, como todos sabemos, el sistema tributario ya no sólo persigue la obtención de fondos públicos.

Ahora bien, este principio no puede verse solamente en los momentos de concepción, regulación y aplicación del tributo, sino que su ámbito se extiende al destino de los fondos obtenidos, pues en virtud de la generalidad todo ingreso tributario debe conformar el patrimonio estatal y por tanto estar concebido en el presupuesto; nunca pueden existir destinatarios especiales, más allá del fondo público y al margen de la ley presupuestaria.

\section{EL PRINCIPIO DE PROGRESIVIDAD Y NO CONFISCATORIEDAD DEL TRIBUTO}

Durante muchísimo tiempo los sistemas fiscales se basaron en la proporcionalidad, manteniendo constante el tipo impositivo sin importar las variaciones de la base imponible. Fue a finales del siglo XIX y principios del XX que comenzaron a establecerse escalas progresivas, lo cual generó gran debate doctrinal, hasta su aceptación generalizada en la actualidad. ${ }^{55}$

De ahí, que Rodríguez Bereijo afirme que "los principios de igualdad y progresividad constituyen el núcleo duro que inspira todo el sistema tributario justo". ${ }^{56}$

Según Neumark la progresividad "se considera como un principio fijación y distribución de cargas tributarias según sea la capacidad contributiva de cada individuo para su pago". ${ }^{57}$ En sentido semejante asevera Rodríguez Bereijo: "a través de él se hace real y efectiva la distribución de la carga según la capacidad económica", ${ }^{8}$ es decir, en virtud de este principio debe pagar más quien mayor capacidad contributiva demuestra.

55 Sobre esta evolución y debate Véase Roa, Arsenio, op. cit., pp. 247- 263.

56 Rodríguez Bereijo, Álvaro, "Jurisprudencia constitucional y principios de la imposición”, Garantías constitucionales del contribuyente, Valencia, Tirant lo Blanc, 1998, p. 165.

57 Neumark, Frits, Principios de la imposición, Madrid, Instituto de Estudios Fiscales, 1994, p. 176.

58 Rodríguez Bereijo, Álvaro, op. cit., pp. 51 y 52. 
Sainz de Bujanda argumenta: "El principio de progresividad, como forma de conseguir la efectiva igualdad, supone que la carga tributaria se reparta en forma más que proporcional, atendiendo al nivel de capacidad contributiva de los contribuyentes". ${ }^{59}$

Si bien esta afirmación resulta bastante clara, no nos dice cómo lograr que la carga tributaria se reparta de manera proporcional, es por esto que García Bueno y Ríos Granados nos esclarecen cuando citan a la Corte de Justicia española:

El cumplimiento de este principio se realiza a través de tarifas progresivas, pues mediante ellas se consigue que cubran un impuesto en monto superior los contribuyentes de más elevados recursos y uno inferior los de menores ingresos, estableciéndose, además, una diferencia congruente entre los diversos niveles de ingresos. ${ }^{60}$

Resulta evidente la relación de este principio con el de capacidad contributiva, pues el principio de progresividad es precisamente el que debe evitar que el aporte sea exagerado en relación con la capacidad contributiva; es decir, el impuesto no debe ser desproporcionado, no debe abarcar demasiado, aún cuando haya manifestación de capacidad contributiva.

A diferencia de otros, como sostiene Calvo Ortega "la progresividad, como principio, se aplica solo a los impuestos" ${ }^{\prime \prime 1}$ y consiste en concebir al tributo de manera que al aumentar la base imponible del contribuyente aumente proporcionalmente el tipo impositivo y por tanto la deuda tributaria.

Según Roa en el impuesto progresivo "a medida que aumenta la cuantía de la materia imponible, se impondrá una fracción cada vez mayor. Así, si por 100 se paga 1 , por 200 se pagarán 2.32 , y por 400 se pagarán 4,80 ". ${ }^{62}$

La progresividad del sistema tributario es un principio que debe apreciarse no sólo al momento de la creación de los tributos, sino que debe abarcar todas las fases de su aplicación, incluso debe llegar hasta el régimen de sanciones.

59 Saínz de Bujanda, Fernando, Lecciones de derecho financiero, 9a. ed., Madrid, Artes Gráficas Benzal, 1991, p. 386.

60 García Bueno, Marco César y Ríos Granados, Gabriela, “Alcance de los principios materiales de justicia tributaria en el sistema tributario mexicano, la capacidad contributiva, la igualdad y la proporcionalidad tributaria", Estudios en homenaje a Héctor FixZamudio, Biblioteca jurídica de la UNAM, www.juridicas.unam.mx, p. 462.

${ }^{61}$ Calvo Ortega, Rafael, op. cit., p. 73.

62 Roa, Arsenio, op. cit., p. 248. 
El principio de no confiscatoriedad nace muy unido a la progresividad, pues fue la Constitución Española de 1978, quien por primera vez lo consigna como un límite de esta.

Tal y como afirma Rodríguez Bereijo el principio de no confiscación es "una de las innovaciones más singulares de nuestra Constitución [se refiere a la mencionada Constitución Española de 1978], sin parangón con otros ordenamientos constitucionales". ${ }^{63}$

Aún cuando este principio no cuenta con gran desarrollo teórico, puede entenderse que se refiere a que el tipo impositivo en los impuestos progresivos no puede seguir aumentando desmedidamente mientras aumente la base imponible, sino que debe tener su límite en el derecho de propiedad. Como sostienen Martín Queralt, Lozano Serrano, Casado Ollero y Tejerizo López:

El principio de confiscación - al que se le ha prestado escasa atención doctrinal - supone, como ha señalado Lasarte, un límite extremo que dimana del reconocimiento del derecho de propiedad, cuya finalidad es impedir una posible conducta patológica de las prestaciones patrimoniales coactivas o una radical aplicación de la progresividad que atentara contra la capacidad económica que la sustenta. ${ }^{64}$

\section{EL PRINCIPIO DE JUSTICIA EN EL GASTO PÚBLICO}

A diferencia de lo que ha sucedido en la doctrina y en la práctica internacional con relación a los ingresos, por mucho tiempo no existieron medios que pudieran sujetar los gastos públicos a criterios de justicia. Su regulación quedaba libre debido a que se entendía que la distribución de los gastos pasaba más por elementos políticos que jurídicos.

Pauner Chulvi, refiriéndose a este punto, resume:

...se afirma que los criterios de aplicación de los gastos públicos son de naturaleza política porque son los distintos grupos políticos que ejercen sucesivamente el poder quienes establecen qué necesidades públicas cubrirá el Estado. De ahí se deduce que los principios a los que cabría someter las

${ }^{63}$ Rodríguez Bereijo, Álvaro, "Jurisprudencia constitucional y principios de la imposición"...,op. cit., p. 174.

64 Martín Queralt, Juan; Lozano Serrano, Carmelo; Casado Ollero, Gabriel y Tejerizo López, José Manuel, op. cit., p.155. 
decisiones sobre la distribución de los gastos públicos son cambiantes como lo son las preferencias de los grupos en el poder. ${ }^{65}$

Evidentemente el hecho de que sea el Estado quien decide en cada momento qué gastos debe realizarse y en qué medida, no entra en contradicción con que esta decisión se tome siguiendo determinados criterios de justicia, por lo que el argumento del carácter político de los gastos resulta insuficiente. Como sostiene Zornoza Pérez:

una cosa es la decisión sobre el volumen de recursos que ha de destinarse al cumplimiento de los distintos fines del Estado que será variable en función de la escasez de recursos y de la concepción política del Gobierno. Otra cosa son los criterios últimos que deben orientar la acción del Estado, los fines que poseen un valor estable. ${ }^{66}$

Fue la Constitución Española de 1978 la que introdujo este principio en el ámbito constitucional. Fuentes Quintana fue quien defendió la enmienda que permitió su inclusión. En los correspondientes trabajos parlamentarios puede leerse:

se trata de constitucionalizar los principios a los que debe responder el gasto público. No resulta aceptable que la Constitución ignore los criterios a que debe responder el gasto público cuando tantos artículos del texto constitucional habrán de traducirse prácticamente en aumentos del gasto del sector público. Por otra parte, la Hacienda Pública no es sólo una Hacienda de ingresos a cuyo comportamiento se refiere la Constitución. Existen gastos públicos también — la otra mitad de la Hacienda Pública — cuya conducta debe orientarse por principios semejantes a los que tratan de gobernar el ingreso público (...). La enmienda que se propone pretende que el gasto público sirva (...) a los principios de la eficiencia y economicidad (requisito obligado para justificar la racionalidad de todo gasto público). ${ }^{67}$

65 Pauner Chulvi, Cristina, El deber constitucional de contribuir a los gastos públicos, tesis doctoral publicada por la Facultad de Ciencias Jurídicas y Económicas, Universitat Jaume I, Valencia, 2000, p. 136.

${ }^{66}$ Zornoza Pérez, Juan J., "El equitativo reparto del gasto público y los derechos económicos y sociales”, Hacienda Pública Española, Madrid, núm. 113, 1988, p. 53.

67 Comentarios a la Constitución Española de 1978, Madrid, VLex, 2006, pp. 442 y 443. 
Este principio está encaminado a lograr coherencia entre la imposición y los gastos públicos, pero sobre todo a que se realice una asignación equitativa de los recursos como garantía de los derechos ciudadanos. La finalidad de los gastos es precisamente la satisfacción de necesidades sociales, por tanto, como bien lo establece la mencionada Constitución Española, la justicia de los gastos se logra siguiendo criterios de economía y eficiencia en su programación, ejecución y control.

\section{EL PRINCIPIO DE RESERVA DE LEY \\ Y SU RELACIÓN CON EL PRINCIPIO DE LEGALIDAD \\ EN EL ÁMBITO TRIBUTARIO}

Según Calvo Ortega: "El precedente de la reserva de ley tributaria es el principio de autoimposición, cuyo nacimiento se sitúa en los siglos XII y XIII: es necesario que la Asamblea, los representantes de determinados estamentos aprueben las peticiones de tributos hechas por el monarca para que estas sean efectivas". ${ }^{68}$ De ahí, que este principio podamos considerarlo como la más clásica garantía del contribuyente.

$\mathrm{Su}$ origen se remonta al comienzo mismo del constitucionalismo, con la máxima nullum tributum sine lege. En esencia este principio hace referencia a que se establezca constitucionalmente que determinados elementos sólo pueden ser regulados por ley, es decir, quedan reservados a la ley.

Respetando dicho principio, desde el siglo XIX hasta la actualidad, las normas financieras han sido promulgadas mediante la ley, con el fin de minimizar cada vez más la actividad discrecional de la administración en cuanto al establecimiento de los tributos y la distribución de los gastos.

Ahora bien, si partimos de considerar que el principio constitucional de legalidad, tal y como lo define Fernández Bulté, debe ser entendido “como una forma de existencia política o un método de dirección estatal (...) que consiste en la promulgación de leyes que expresan patrones conductuales (...) que deben ser cumplidos estrictamente por el Estado, las organizaciones sociales y políticas y los ciudadanos", ${ }^{69} \mathrm{o}$ como, en ese mismo sentido, sostiene Rubio Llorente: "es un principio estructural que determina la for-

${ }^{68}$ Calvo Ortega, Rafael, op. cit., p. 78.

69 Fernández Bulté, Julio, Teoría del derecho, La Habana, Félix Varela, 2002, pp. 237 y 239. 
ma política"; $; 0$ entonces se concibe a la legalidad no como un equivalente del principio de reserva, sino de modo totalmente distinto, constituyendo el principio de legalidad tributaria, una manifestación específica del principio constitucional de legalidad.

A primera vista pareciera que resulta suficiente con la regulación del principio de legalidad tributaria, para limitar la actuación de la administración, buscando mayor justicia en la imposición y en consecuencia, mayores garantías para el contribuyente. No obstante, como bien afirma Rubio Llorente, haciendo referencia a exposiciones de Ignacio de Otto: "El simple juego del principio de legalidad, cuyas exigencias quedan satisfechas con una simple cláusula de habilitación, apenas ofrece (...) seguridad alguna frente al uso que el Gobierno pueda hacer de la potestad reglamentaria". ${ }^{71}$

El principio de legalidad tributaria es aquel mediante el cual todo acto realizado por la administración tributaria, ya sea concreto o abstracto, debe tener su fundamento en una ley previa, pues la administración no puede por sí misma crear, modificar o anular tributos, deberes o derechos si una ley no los ha establecido o no la ha habilitado para ello.

Desde este punto de vista, el cumplimiento del principio de legalidad implica, en el mejor de los casos, que el establecimiento del tributo deba realizarse por ley (formal y material), o simplemente que exista una ley que faculte a determinada autoridad, ya sea el Ejecutivo o la administración, para el establecimiento de tributos, con lo cual, también se estaría actuando según lo dispone la ley.

Esta segunda opción no recibe mucho apoyo por parte de la doctrina, pues como plantea Valdés Costa:

El panorama general es el de que la descentralización en materia tributaria no es la mejor solución para satisfacer las necesidades financieras locales. Los sistemas tributarios contemporáneos basados en los impuestos sobre la renta, al patrimonio y los consumos, requieren, por su importancia económica y social una regulación armónica desde el punto de vista nacional, incompatible con la dispersión de las competencias legislativas. ${ }^{72}$

70 Rubio Llorente, Francisco, "El principio de legalidad", Revista Española de Derecho Constitucional, año 13, núm. 39, septiembre-diciembre 1993, p. 13.

71 Ibidem, p. 24.

72 Valdés Costa, Ramón, op. cit., p. 231. 
El principio de reserva de ley viene entonces a complementar y reforzar el principio de legalidad, y en consecuencia no pueden equipararse, pues la reserva está encaminada a imponer al legislador la obligación de regular determinadas materias, sin delegaciones.

Sólo a través de la regulación constitucional del principio de reserva de ley se limitan las posibles injerencias del ejecutivo y se logra que el legislador no pueda disponer del principio y se vea obligado a legislar.

En este punto existe bastante consenso entre los autores, lo que no resulta así cuando nos referimos a qué materias tributarias son las que sólo deben regularse por ley. Pérez Royo, refiriéndose a este tema, señala:

En relación a esta cuestión, la doctrina ha solido distinguir, al tratar de manera general la institución de la reserva de ley en la Constitución, entre reserva absoluta y meramente relativa. En el primer supuesto, la Ley debe llevar a cabo de manera acabada la completa regulación de la materia a ella reservada, sin dejar espacio para la integración de su disciplina por una fuente distinta. En cambio, en el caso de la reserva relativa, la Ley puede limitarse a establecer los principios y criterios dentro de los cuales la concreta disciplina de la materia reservada podrá posteriormente ser establecida, en todo o en parte, por una fuente secundaria.

Entonces, qué principios y criterios deben considerarse, en materia tributaria, como orientadores o fundamento de todo el sistema. Calvo Ortega resuelve esta disyuntiva cuando sostiene:

Si nos apoyamos en la finalidad actual y más moderna de los tributos (...) los elementos esenciales son el hecho imponible (el nacimiento de una obligación), la base imponible y el tipo de gravamen (cuantificación) (...) y la determinación del contribuyente (qué sujeto concreto es deudor). Hay que añadir las infracciones y sanciones tributarias como manifestación concreta del derecho sancionador siempre cubierto por la reserva en todos sus tipos concretos. Finalmente la importancia social y económica de una determinada materia justifica la extensión de la reserva a que nos referimos a las exenciones tributarias. ${ }^{73}$

Todos estos elementos han pasado a conformar en la modernidad los denominados Estatutos del Contribuyente.

73 Calvo Ortega, Rafael, op. cit., p. 79. 
Ahora bien, todas las materias no cubiertas por la reserva no quedan abiertas libremente a la facultad reglamentaria de la administración, sino que esta sólo puede reglamentarlas siempre y cuando cuente con una cláusula legal previa que la faculte.

En resumen podemos afirmar que la reserva de ley se convierte en verdadera garantía para el contribuyente debido fundamentalmente a tres aspectos básicos: en primer lugar ofrece legitimidad a la tributación, ya que mediante este principio sólo el órgano legislativo electo popularmente es quien establece los tributos; segundo, garantiza que las cuestiones fundamentales de la tributación no sean reguladas por una norma de inferior jerarquía; y por último, evita situaciones de doble imposición y contradicciones en el sistema de impuestos, tasas y contribuciones, lo que podría fomentarse si fueran varios órganos los que tuvieran estas facultades.

\section{EL PRINCIPIO DE IGUALDAD}

Este principio, al decir de Calvo Ortega, "es un tipo especial de la igualdad ante la ley recogida normalmente en los textos constitucionales"; ${ }^{74} \mathrm{de}$ ahí que no requiera una regulación especial o diferente..$^{75}$ Como sostiene Uckmar pudiéramos considerar que el principio constitucional de igualdad se manifiesta en el derecho tributario en un doble ámbito:

a) En sentido jurídico, como paridad de posiciones, excluyendo los privilegios de clase, de raza y de religión, en manera que los contribuyentes se encuentren en iguales circunstancias y puestos ante un mismo régimen fiscal.

b) En sentido económico, es la obligación de contribuir a las cargas públicas en igual medida, entendido en términos de sacrificio y (...) en relación con la capacidad contributiva de cada uno. ${ }^{76}$

74 Ibidem, p. 75.

75 Al tratarse de un único principio, el principio constitucional de igualdad, regularlo de manera independiente para el ámbito tributario, pudiera resultar repetitivo e innecesario. Corresponde al legislador y a los operadores jurídicos respetarlo, desarrollarlo y aplicarlo según ataña.

76 Uckmar, Víctor, Principios comunes del derecho constitucional tributario, Bogotá, Temis, 2002, p. 59. 
Desde el punto de vista jurídico el principio de igualdad guarda estrecha relación con el principio de generalidad. Como habíamos visto al tratar este último principio, la generalidad viene a garantizar una de las manifestaciones de la igualdad, pues esta exige, en su plano formal, que todas las personas tributen sin distinción de edad, sexo, color de la piel, nacionalidad u otras diferenciaciones.

No obstante, como sostiene Javier Pérez Royo

...el principio de igualdad es, en el constitucionalismo contemporáneo, un principio de no discriminación, ya que no se prohíbe cualquier diferencia de trato en el ejercicio de los derechos y libertades, sino que, (...) el principio de igualdad solo resulta vulnerado cuando dicha diferencia de trato está desprovista de una justificación objetiva y razonable, es decir, cuando es discriminatoria. ${ }^{77}$

Por tanto, esta simple igualdad formal, no constituye un criterio de justicia acabado, pues la igualdad material o real depende del establecimiento de diversas diferencias de trato jurídico en favor de determinados contribuyentes, concebidos en el texto constitucional.

No podemos desvirtuar el hecho de que "la igualdad real es la misma igualdad formal cuando entra en juego algún criterio de diferenciación de trato jurídico en favor de grupos sociales en desventaja previsto por el constituyente o el legislador". ${ }^{78}$

Como bien sostienen Bilbao Ubillos y Rey Martínez la "discriminación no es cualquier diferenciación, en el sentido más neutro de la palabra, sino aquélla que se funda en un prejuicio negativo en virtud del cual los miembros de un grupo son tratados como seres no ya diferentes sino inferiores (en ciertos aspectos, al menos)". ${ }^{79}$

Esta diferencia de trato se logra, en el derecho tributario, a través de la institución de las denominadas exenciones, las que son admitidas siempre

77 Pérez Royo, Javier, Curso de derecho constitucional, Madrid, Marcial Pons, 2001, pp. 282 y 283.

78 Carbonell, Miguel (comp.), El principio constitucional de igualdad, México, Comisión Nacional de los Derechos Humanos, 2003, p. 109.

79 Ibidem, p. 111. 
y cuando estén "basadas en criterios razonables, fundados y no arbitrarios que tengan acogida en el ordenamiento". ${ }^{80}$

Desde el punto de vista económico no basta, para satisfacer el principio de igualdad, con que todos contribuyan sin discriminaciones, sino que, además, deben hacerlo en la misma cuantía. En este punto viene a jugar un papel esencial el principio de capacidad contributiva, pues es quién garantiza que quienes se encuentren en una situación económica similar contribuyan de en la misma medida.

En sentido general la igualdad tributaria debe ser concebida no sólo en el momento de creación de la ley, sino también en el momento de su aplicación, pues este principio vincula no sólo al legislador, sino también a los operadores jurídicos.

La igualdad ante la ley garantiza que todos contribuyan sin distinciones discriminatorias y que situaciones económicas iguales reciban igual tratamiento, teniendo en cuenta que la capacidad contributiva que se pone de manifiesto es la misma, mientras que la igualdad en la aplicación de la ley exige que tanto los contribuyentes como la administración tributaria cuando se encuentren en la misma situación deban ser sometidos a la misma ley, a la misma jurisdicción, y con las mismas garantías.

En conclusión: a) el principio de igualdad en el ámbito tributario se traduce en el respeto al principio de capacidad económica, de forma que situaciones económicamente iguales deben ser tratadas de la misma manera; b) el principio de igualdad no veda cualquier desigualdad, sino sólo aquella que pueda reputarse como discriminatoria, por carecer de justificación; c) el principio de igualdad no sólo exige la igualdad ante la ley, sino también la igualdad en la aplicación de la ley; d) el principio de igualdad debe interpretarse en conexión con las exigencias derivadas de otros principios constitucionales; e) la igualdad en el marco del sistema tributario debe complementarse con la igualdad en el ordenamiento del gasto público, lo que se traduce en la necesidad de asignar equitativamente los recursos públicos. ${ }^{81}$

${ }^{80}$ Martín Queralt, Juan; Lozano Serrano, Carmelo; Casado Ollero, Gabriel y Tejerizo López, José Manuel, op. cit., p. 336.

81 Ibidem, p. 154. 


\section{LAS CONSTituciones Vigentes EN CubA Y LOS PRINCIPIOS DE JUSTICIA TRIBUTARIA}

Varias son las constituciones que han estado vigentes en Cuba a lo largo de su historia. Debido a su conquista y posterior colonización española, la nación cubana sufrió alrededor de cuatro siglos de dominación colonial, por lo que la primera legislación vigente en nuestro país fue completamente elaborada en España. No es hasta el inicio de las luchas por la independencia, que podemos comenzar a hablar de constituciones puramente cubanas, las que, debido al estado de beligerancia, no rigieron en toda la isla, sino que cohabitaron con el derecho español, dándose un caso sui géneris de pluralismo jurídico.

Después de concluidas la guerra iniciada por José Martí y la primera intervención norteamericana comenzó en Cuba un periodo marcado por su carácter neocolonial. En esta etapa se sucedieron varios textos constitucionales, dentro de los cuales resalta la Constitución de 1940, la cual rigió hasta el triunfo revolucionario el 1o. de enero de 1959, con la excepción del periodo (1952-1954) en que estuvieron vigentes los Estatutos Constitucionales del tirano Fulgencio Batista.

El nuevo gobierno revolucionario puso en vigor la conocida como Ley Fundamental de 1959, hasta que en 1976 se promulga la actual Constitución vigente en Cuba, la primera Constitución socialista de nuestra historia.

\section{El CONSTITUCIONALISMO ESPAÑOL VIGENTE EN CUBA} (1812-1869)

La Constitución Española del 18 de marzo de 1812 fue la primera Constitución que conoció Cuba. La Constitución de Cádiz, estuvo rigiendo en nuestro país hasta 1814, a partir del cual comenzó un periodo de cierta inestabilidad en su vigencia, pues aunque en España fue cesada en ese año, restaurada en 1820 , vuelta a cesar en 1823 y restaurada nuevamente en 1836, en Cuba no se conoció este hecho hasta ese último año, en el que tampoco se reconoció su vigor en toda la isla.

Su artículo 8o. regulaba el deber constitucional de contribuir a los gastos públicos, al establecer claramente que "También está obligado todo espa- 
ñol, sin distinción alguna, a contribuir en proporción de sus haberes para los gastos del Estado". ${ }^{82}$

Esta carta magna postulaba un conjunto de elementos propios del liberalismo, como es el caso del principio de igualdad, aunque su regulación es limitada y no claramente expresa. Varela explicando esta Constitución sostiene:

la igualdad legal se halla en la distribución de los derechos, y es la única que no va acompañada de desigualdad en las operaciones, pues lo mismo debe decidirse el derecho de un pobre, que el de un rico (...), supuesto que no dependen de la opinión que se tiene de las personas, ni de lo que estas puedan prometer, sino de la naturaleza de los hechos sobre que se juzga. ${ }^{83}$

En el artículo 248 establecía: "En los negocios comunes, civiles y criminales no habrá más que un solo fuero para toda clase de personas", ${ }^{84} \mathrm{con}$ lo cual se estaba haciendo alusión a la igualdad jurídica o igualdad ante la ley, la que se conformaba en el ámbito tributario, como afirma Bonell Colmenero "por la prohibición regia de conceder privilegios a personas o corporaciones", ${ }^{85}$ lo cual disponía el artículo 172.8: "Las restricciones de la autoridad del Rey son las siguientes: No puede el Rey imponer por sí directa ni indirectamente contribuciones, ni hacer pedidos bajo cualquier nombre o para cualquiera objeto que sea, sino que siempre los han de decretar las Cortes". 86

La presencia de los principios de generalidad tributaria y capacidad contributiva podríamos defenderla a partir de la regulación del artículo 339, el que establecía: "Las contribuciones se repartirán entre todos los españoles con proporción a sus facultades, sin excepción ni privilegio alguno". ${ }^{87}$

La generalidad quedaría conformada con la expresión "las contribuciones se repartirán entre todos los españoles sin excepción ni privilegio alguno", ya que de esta forma se está estableciendo la obligación de todos de tributar

82 Constitución de Cádiz, http://www.cervantesvirtual.com/portal/Constituciones/españolas/Cádiz1812

83 Varela, Félix, op. cit., 1977, p. 41.

84 Constitución de Cádiz, op. cit.

85 Bonell Colmenero, Ramón, "Principio de igualdad y deber de contribuir", Anuario Jurídico y Económico Escurialense, núm. 38, 2005, p. 180.

${ }^{86}$ Constitución de Cádiz, op. cit.

87 Idem. 
sin discriminaciones, mientras que el principio de capacidad contributiva se desprende del enunciado "con proporción a sus facultades", el cual da la idea de que el tributo se impondrá teniendo en cuenta la posibilidad económica de cada cual, sobre lo que cada cual posea.

Otros dos principios cuya regulación fiscal parece bastante clara son el principio de legalidad y el principio de reserva de ley. El artículo 7o. de la Constitución regula que "Todo español está obligado a ser fiel a la Constitución, obedecer las leyes y respetar las autoridades establecidas", ${ }^{88}$ palabras que claramente se refieren a la supremacía de la ley con respecto al resto de las normas jurídicas, y a la obligación que tienen todos de respetarla. Este precepto, además, postula el principio de constitucionalidad, al establecer expresamente el lugar cimero de la Carta Magna en la pirámide normativa.

La regulación del principio de reserva de ley podemos apreciarla de la relación de varios apartados. El artículo 338, que corresponde al capítulo VII, De las contribuciones, dispone: "Las Cortes establecerán o confirmarán anualmente las contribuciones, sean directas o indirectas, generales, provinciales o municipales, subsistiendo las antiguas, basta que se publique su derogación o la imposición de otras". ${ }^{89}$ Este precepto faculta a las Cortes como único órgano capaz de establecer tributos, lo cual se establece explícitamente en el apartado decimotercero del artículo 131: "Las facultades de las Cortes son: Establecer anualmente las contribuciones e impuestos", ${ }^{90}$ y queda totalmente ratificado por el artículo 172.8 cuando enumera como una de las restricciones de la autoridad del Rey, la de "imponer por sí directa ni indirectamente contribuciones, ni hacer pedidos bajo cualquier nombre o para cualquiera objeto que sea, sino que siempre los han de decretar las Cortes". ${ }^{91}$ Por su parte el apartado primero del propio artículo 131 establece como otra de las facultades de las Cortes "Proponer y decretar las leyes, e interpretarlas y de rogarías en caso necesario", ${ }^{92}$ sin que se le faculte expresamente para emitir otro tipo de disposición jurídica; por lo que, interpretando sistémicamente la Constitución, podemos entender que las contribuciones sólo podían establecerse por ley, con lo cual quedaba configurado el principio de reserva de ley. 
En el periodo comprendido entre 1834 y 1836, en que no se encontraba en vigor la Constitución de Cádiz, rigió en España y en Cuba, el Estatuto Real de España, promulgado por Real Decreto del 10 de abril de 1834 y en Cuba, del 5 de junio del propio año. Este Estatuto, pobre en su conformación y propio del despotismo, resaltaba el poder del Rey a través de numerosas facultades que limitaron las competencias de las Cortes Generales.

En relación a la materia que nos ocupa el artículo 33 establecía que no se podían exigir contribuciones acordadas por las Cortes si no hubiese mediado la propuesta del rey, mientras que en el artículo 35 de regulaba: "siendo preciso que antes de votarlas se les presente por los respectivos Secretarios de despacho una exposición en la que se manifieste el estado que tengan los varios ramos de la Administración Pública, debiendo después el Ministerio de Hacienda presentar a las Cortes el presupuesto de gastos". ${ }^{93}$

Si bien esta regulación no constituye ninguna garantía para el contribuyente, al menos de su articulado se desprende una necesaria correlación entre ingresos y gastos.

En 1837, cuando la Constitución de 1812 ya había entrado en vigor por segunda vez mediante Real Decreto del 13 de agosto de 1836, se les impidió, a los diputados cubanos, que tomaran posesión en las Cortes Generales de España, alegándose que esta Constitución, en lo concerniente a la representación, no era aplicable a las colonias.

Los diputados cubanos protestaron ante este acto, pero como narra Lezcano y Mazón:

En definitiva, por Real Orden del 25 de abril de 1837 se dijo a los Gobernadores, Capitanes Generales de las Islas de Cuba y Puerto Rico que S. M. la Reina Gobernadora, por Real orden de 19 de dicho mes, mandó publicar y circular la disposición de las Cortes para que las provincias de América y Asia sean regidas y administradas por leyes especiales y análogas a su respectiva situación y circunstancias propias para hacer su felicidad, y que en consecuencia no tomen asientos en las Cortes actuales diputados por las expresadas provincias. ${ }^{94}$

A partir de este momento Cuba volvió a regirse por las leyes de Indias, además de reglamentos y reales órdenes que se dictaron.

93 Lezcano y Mazón, Andrés M., Las Constituciones de Cuba, Cultura Hispánica, Madrid, 1952, p. 30.

94 Ibidem, p.19. 


\section{LAS PRIMERAS CONSTITUCIONES CUBANAS \\ FRUTO DE LAS GUERRAS INDEPENDENTISTAS DEL SIGLO XIX}

(1869-1899)

Las primeras Constituciones genuinamente cubanas fueron dictadas después de iniciadas las guerras de independencia. La Constitución de Guáimaro de 1869, fue la primera, y a pesar de las circunstancias históricas, sí se refirió a algunos principios tributarios.

En su artículo 14 se regulaba el principio de reserva de ley, al disponerse que:

Deben ser objeto indispensable de ley las contribuciones, los empréstitos públicos, la ratificación de los tratados, la declaración y conclusión de la guerra, la autorización al Presidente para conceder patentes de corso, levantar tropas y mantenerlas, proveer y sostener una armada, y la declaración de represalias con respecto al enemigo. ${ }^{95}$

Lo cual, como ya hemos visto, constituye, además de un principio formal ordenador de la materia tributaria, una garantía para el contribuyente.

Mesquida del Cueto defiende que "como no se hace pronunciamiento alguno de otro órgano con facultades legislativas y éstas adquirieron obligatoriedad (artículo 10), la reserva de ley se entiende absoluta". ${ }^{96}$ Coincidimos en este aspecto, sobre todo teniendo en cuenta que el artículo 13 disponía: "Acordada por segunda vez una resolución de la Cámara, la sanción será forzosa para el Presidente", ${ }^{97}$ con lo cual, en última instancia, el presidente tenía que respetar la decisión del órgano legislativo, aún cuando en un principio podía presentar objeciones y regresar el proyecto a la Cámara.

Otro principio que se pone de manifiesto en este texto es el de igualdad, el cual puede inferirse de la regulación del artículo 26: "La República no reconoce dignidades, honores especiales ni privilegio alguno". ${ }^{88}$ En este sentido autores como Mesquida del Cueto ${ }^{99}$ consideran que este artículo, llevándolo al plano tributario, es contentivo del principio de generalidad tributaria, lo cual consideramos que se trata de una interpretación demasiado

95 Ibidem, p. 504.

96 Mesquida del Cueto, Raysa, "Disposiciones constitucionales de interés sobre materia fiscal”, Apuntes de derecho financiero cubano, La Habana, Félix Varela, 2007, p. 421.

97 Lezcano y Mazón, Andrés M., op. cit., p. 504

98 Idem.

99 Véase Mesquida del Cueto, Raysa, op. cit., p. 421. 
amplia o extensiva. Considerar que estamos en presencia del principio de generalidad implicaría interpretar este precepto en el sentido de que todas las personas que se encuentren en una situación susceptible de ser gravada deben soportar la carga tributaria sin tratos desiguales, lo cual no puede afirmarse, pues la regulación del precepto expresamente no se refiere a la obligación de tributar de todo el que manifieste capacidad contributiva sin distinción, sino que sólo expresa la prohibición de establecer desigualdades.

Las siguientes Constituciones fueron la de Baraguá en 1878 y la de Jimaguayú en 1895, pero ninguna estableció precepto alguno en materia fiscal que estuviera dedicado a proteger al contribuyente, lo cual no ha de extrañarnos si tenemos en cuenta que se trata de constituciones dictadas en tiempo de guerra.

El 29 de octubre de 1897, se dictó la Constitución de la Yaya, la que, aunque regula algunos preceptos fiscales, tampoco se refiere a principios de justicia tributaria.

El artículo 7o. establece que "Nadie podrá ser compelido a pagar otras contribuciones que las acordadas por autoridad competente", ${ }^{100}$ mientras que en el artículo 22 apartados 1 y 11 se dispone que "Son atribuciones del Consejo de Gobierno, además de las estatuidas por otros artículos de esta Constitución: 1. Dictar todas las Leyes y Disposiciones relativas al Gobierno de la Revolución y a la vida militar, civil y política del Pueblo Cubano, y 11. Imponer contribuciones, decretar la inversión de los fondos públicos y pedir y aprobar cuentas de la misma". ${ }^{101}$

Estos preceptos pudieran interpretarse como la regulación del principio de reserva de ley, al estilo de la Constitución de Cádiz, pero al establecer el artículo decimoquinto que "El Poder Ejecutivo está investido en un Consejo de Gobierno, que tendrá la facultad de dictar leyes y reglamentos de carácter general conforme a la Constitución", ${ }^{102}$ no podemos sustentar la presencia del tal principio. El mencionado Consejo de Gobierno, no es un órgano legislativo, sino el poder ejecutivo investido de facultades legislativas, y, por si fuera poco, puede crear contribuciones mediante reglamentos;

100 Lezcano y Mazón, Andrés M., op. cit., p. 520.

101 Ibidem, pp. 522 y 523.

102 Ibidem, p. 521. 
elementos todos que se contraponen totalmente a la esencia del principio de reserva de ley. ${ }^{103}$

El primero de mayo de 1898 fue implantada en Cuba, en plena guerra de independencia, mediante Real Decreto, del 25 de noviembre de 1897, la denominada Constitución autonómica, la que entró en vigor paralelamente a la Constitución de la Yaya, que regía para la República en armas. Esta Constitución duró muy poco tiempo y no reguló ningún precepto fiscal de interés para el contribuyente.

\section{LAS CONSTITUCIONES CUBANAS DEL SIGLO XX NEOCOLONIAL (1901-1959)}

Al final de la primera intervención norteamericana en Cuba se aprobó la Constitución de 1901, que entró en vigor en 1902. En este texto se reguló por primera vez en el constitucionalismo cubano, de forma directa y clara, el deber de contribuir de los ciudadanos cubanos y extranjeros. El artículo 9.2 establecía: "Todo cubano está obligado: A contribuir para los gastos públicos, en la forma y proporción que dispongan las leyes", ${ }^{104}$ mientras que el artículo 10.6 regulaba: "Los extranjeros residentes en el territorio de la República, se equiparan a los cubanos: en cuanto a la obligación de contribuir a los gastos públicos del Estado, la Provincia y el Municipio". ${ }^{105}$

Sobre este particular advierte Ugarte:

Son estas disposiciones en extremo latas como no podían menos de serlo en un una Constitución; y corresponde a los legisladores, al redactar las leyes secundarias que las desarrollen, expresar con la mayor claridad posible cuales son los servicios que la patria tiene derecho a demandar de sus hijos, y excogitar la forma menos gravosa en lo personal, y onerosa en lo pecuniario, de prestar esos servicios. De nada servirían los buenos propósitos de los constituyentes, si al llevar a la práctica sus disposiciones vinieran a convertirse en carga abrumadora para el pueblo. Las obligaciones y derechos entre el Estado y los ciudadanos deben ser correlativos y proporcionales, por que el espíritu de justicia inclina más que la imposición al cumplimiento del

103 Este análisis pudiera aplicarse a la Constitución de 1895, ya comentada, y a la Constitución autonómica, pues las regulaciones sobre el Consejo de Gobierno fueron similares.

${ }^{104}$ Lezcano y Mazón, Andrés M., op. cit., p. 549.

105 Ibidem, p. 550. 
deber. Las leyes que tienen por base la equidad no necesitan presión alguna para aceptarse: la aceptación es voluntaria, y por consiguiente de efectos más valiosos. ${ }^{106}$

El principio de igualdad podemos encontrarlo de manera expresa en la regulación del artículo 11, el que establece que "Todos los cubanos son iguales ante la Ley. La República no reconoce fueros ni privilegios personales". ${ }^{107}$

Otro principio de justicia tributaria que quedó establecido fue el de reserva de ley. El artículo 59 en sus numerales 1 y 8 planteaba que eran atribuciones del Congreso "Formar los Códigos y las leyes de carácter general" y "Establecer las contribuciones e impuestos de carácter nacional, que sean necesarios para las atenciones del Estado"; ${ }^{108}$ por lo que de cierta forma quedaba configurado el principio de reserva de ley, el cual era relativo porque el Presidente de la República, según el artículo 68.1 tenía entre sus atribuciones:

Sancionar y promulgar las leyes, ejecutarlas y hacerlas ejecutar; dictar cuando no lo hubiere hecho el Congreso, los reglamentos para la mejor ejecución de las leyes; y expedir, además, los decretos y las órdenes que, para este fin y para cuanto incumba al gobierno y Administración del Estado, creyere convenientes, sin contravenir en ningún caso lo establecido en dichas leyes. ${ }^{109}$

La regulación del artículo 34: "Nadie está obligado a pagar contribución ni impuesto que no estuvieren legalmente establecidos, y cuya cobranza no se hiciere en la forma prescripta por las leyes", confirma la presencia de este principio de reserva de ley en el texto, si entendemos que cuando se refiere a "legalmente" está haciendo alusión a legalidad concebida como respeto a la ley en sentido estricto y no a cualquier norma jurídica.

La Constitución de 1934, Constitución del gobierno provisional, también reguló el deber de contribuir, al establecer en su artículo 9, apartado tercero, que "Todo cubano está obligado a contribuir a los gastos públicos en la forma y proporción que dispongan las leyes". ${ }^{110}$ Esta última expresión pudiera

106 Ugarte, Ángel, Comentarios a la Constitución de Cuba, La Habana, Talleres tipográficos Solana y Compañía, La Habana, 1918, p. 13.

107 Lezcano y Mazón, Andrés M., op. cit., p. 550.

108 Ibidem, pp. 563 y 564.

109 Ibidem, p. 567.

110 Ibidem, p. 629. 
hacernos pensar en la referencia al principio de reserva de ley, sobre todo si tenemos en cuenta que el artículo 35, dispone que "nadie está obligado a pagar contribución, impuesto ni multa, tenga esta o no carácter penal, que no estuvieren establecidos por las Leyes y cuya cobranza no se hiciere en la forma prescrita por las mismas". ${ }^{111}$

A pesar de estos preceptos no puede sostenerse la presencia de la reserva, teniendo en cuenta, sobre todo, la regulación del artículo 56, apartado octavo, que faculta al Consejo de Secretarios para "establecer las contribuciones e impuestos de carácter nacional que sean necesarios para satisfacer las necesidades del Estado", con lo cual, expresamente, se le estaba dando al poder ejecutivo la facultad de crear tributos.

De su articulado también se desprende la presencia del principio de igualdad (artículo 11).

La Ley Constitucional de 1935 también previó el principio de reserva de ley de modo relativo, al estilo de la Constitución de 1901.

El artículo 60 establecía: "Son atribuciones propias del Congreso, que no podrá delegar: Primero. Formar los Códigos y las Leyes de carácter general, y Octavo: Establecer las contribuciones e impuestos de carácter nacional que sean necesarios para las atenciones del Estado", 112 mientras que el artículo 69 disponía que:

Corresponde al Presidente de la República: Primero. Sancionar y promulgar las Leyes, ejecutarlas y hacerlas ejecutar; dictar, cuando no lo hubiere hecho el Congreso, los Reglamentos para la mejor ejecución de las leyes, y expedir además los Decretos y las Órdenes que para este fin y para cuanto incumba al gobierno y Administración del Estado creyere conveniente, sin contravenir en ningún caso lo establecido en dichas leyes. ${ }^{113}$

La Constitución de 1940, considerada por algunos la Constitución más importante de la historia de Cuba, ${ }^{114}$ tampoco fue demasiado fructífera en materia de principios tributarios, pero introdujo algunos elementos significativos.

111 Ibidem, p. 637.

112 Ibidem, pp. 736 y 737

113 Ibidem, p. 740.

114 Véase Céspedes, Carlos Manuel de, "Aproximación a la Constitución de 1940", Encuentro de la Cultura cubana, núm. 24, Madrid, 2002; Carbonell Cortina, Néstor, El espíritu de la Constitución de 1940, Madrid, Playor, 1974. 
En sus artículos 9 inciso b) y 19 inciso e) regula lo concerniente al deber de tributar. El artículo 9 establece: "Todo cubano está obligado: a contribuir a los gastos públicos en la forma y cuantía que la Ley disponga", ${ }^{115}$ y el artículo 19 equipara los extranjeros residentes a los cubanos "en la obligación de contribuir a los gastos públicos en la forma y cuantía que la Ley disponga". ${ }^{116}$

El principio de igualdad está regulado en el título IV, Derechos fundamentales, sección primera De los derechos individuales, artículo 20, que establece: "Todos los cubanos son iguales ante la Ley. La República no reconoce fueros ni privilegios. Se declara ilegal y punible toda discriminación por motivo de sexo, raza, color o clase, y cualquiera otra lesiva a la dignidad humana. La Ley establecerá las sanciones en que incurran los infractores de este precepto". ${ }^{117}$

Digno es de resaltar el artículo 45 que se refiere a que el régimen fiscal se aplicará de acuerdo con las normas de protección a la familia establecida en la Constitución, pues podríamos interpretarlo como una forma de establecer el principio de justicia en el tributo y sobre todo en el gasto público.

El artículo 91 por su parte también resulta muy interesante, en él se dispone que:

El padre de familia que habite, cultive y explote directamente una finca rústica de su propiedad, siempre que el valor de esta no exceda de dos mil pesos, podrá declararla con carácter irrevocable como propiedad familiar, en cuanto fuere imprescindible para su vivienda y subsistencia y quedará exenta de impuestos y será inembargable e inalienable salvo por responsabilidades anteriores a esta Constitución. Las mejoras que excedan de la suma anteriormente mencionada abonarán los impuestos correspondientes en la forma que establezca la Ley. ${ }^{118}$

Si analizamos con detenimiento este artículo podemos considerar que, aunque no esté regulado de manera general y abstracta como debe ser, en este caso pudiéramos estar en presencia de una regulación casuística del principio de exención del mínimo vital, lo cual es muy avanzado, aunque la regulación sea deficiente.

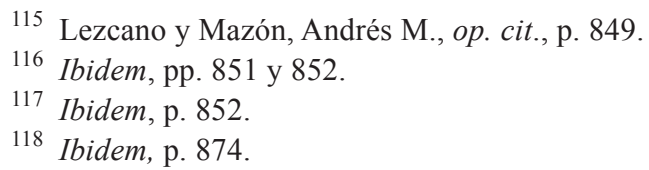


También se tuvo en cuenta en este texto la regulación del principio de reserva de ley de forma relativa, al igual que en la Constitución de 1901 y 1935. El artículo 134 en sus incisos a) y b) establece: "Son facultades no delegables del Congreso: a) Formar los códigos y las leyes de carácter general (...) b) Establecer las contribuciones e impuestos de carácter nacional que sean necesarios para las atenciones del Estado". ${ }^{119}$ De la relación de estos dos artículos puede interpretarse la presencia del mencionado principio, ampliado además por la regulación del artículo 263: "Nadie estará obligado al pago de impuesto, tasa o contribución alguna que no haya sido establecido expresamente por la Ley o por los municipios, en la forma dispuesta por esta Constitución y cuyo importe no vaya a formar parte de los ingresos del presupuesto del estado, la provincia o el municipio, salvo que se disponga otra cosa en la Constitución o en la ley.

No se considerarán comprendidas en la disposición anterior las contribuciones o cuotas impuestas por la Ley con carácter obligatorio a las personas o entidades integrantes de una industria, comercio o profesión, en favor de sus organismos reconocidos por la Ley". ${ }^{20}$

La reserva de ley es relativa si tenemos en cuenta que el artículo 142 inciso a) dispone:

Corresponde al Presidente de la República, asistido del Consejo de Ministros: a) Sancionar y promulgar las leyes, ejecutarlas y hacerlas ejecutar; dictar, cuando no lo hubiere hecho el Congreso, los reglamentos para la mejor ejecución de las mismas; y expedir los decretos y las órdenes que para este fin y para cuanto incumba al gobierno y administración del Estado, fuere conveniente, sin contravenir, en ningún caso, lo establecido en las leyes. ${ }^{121}$

Esta regulación no es suficientemente garantista, pues como bien sostiene Menocal y Barreras: "no basta que el impuesto sea creado por una ley o que se establezca para cubrir necesidades públicas, sino que la Constitución, para proteger al ciudadano contra posibles arbitrariedades, impone que la ley fiscal debe presentar determinadas peculiaridades de precisión y así es

119 Lezcano y Mazón, Andrés M., op. cit., p. 890.

120 Ibidem, p. 938.

121 Ibidem, p. 895. 
que la obligación de pagar impuestos está supeditada a la forma y cuantía que la ley dispone....". ${ }^{122}$

Los gobiernos municipales, en su ámbito, tenían la facultad de crear impuestos (artículo 211), aunque como sostiene Menocal y Barreras: "En general (...) la facultad o atribución de establecer impuestos se concede al Congreso en el orden sustancial y el Ejecutivo interviene sólo en aspectos complementarios o reglamentarios..." ${ }^{123}$ tal y como habíamos visto.

En 1952, el tirano Fulgencio Batista impuso sus Estatutos Constitucionales, los cuales no aportaron nada nuevo en materia de protección al contribuyente, pues recogieron los elementos principales de la Constitución de 1940. ${ }^{124}$

\section{EL FRANCO DECLIVE DE LA TRIBUTACIÓN EN CUBA: EL PERIODO DE PROVISIONALIDAD (1959-1976)}

Con el triunfo de la revolución cubana el 1o. de enero de 1959 comenzó, para la tributación y el derecho tributario, un periodo de franco descenso en nuestro país. La Ley Fundamental de 1959 prácticamente puso en vigor la Constitución de $1940,{ }^{125}$ por lo menos en materia tributaria fue así, y aunque se dictaron algunas leyes durante el periodo, la tendencia fue hacia la disminución paulatina de la imposición.

Mucho tuvo que ver con este hecho las nuevas políticas económicas ${ }^{126}$ que se pusieron en práctica en nuestro país, y en consecuencia las nuevas condiciones de la economía cubana. En un principio las transformaciones económicas se fueron dando dentro del mismo sistema anterior, pero resul-

122 Menocal y Barreras, Juan M., Derecho fiscal. Constitución, legislación y jurisprudencia cubanas, La Habana, Minerva,1958, p. 9.

123 Ibidem, p. 16.

124 Ibidem, pp. 25 y ss.

125 "La Ley Fundamental se concibe sobre la base de la Constitución de 1940, la cual reproduce en numerosos contenidos y acápites, si bien introduce modificaciones en un grupo de artículos y de disposiciones transitorias, algunas de fondo y otras simplemente de forma, al cambiar la denominación de órganos e instituciones". Villabella Armengol, Carlos Manuel, Historia constitucional y poder politico en Cuba, Camagüey, Ácana, 2009, p. 77.

${ }^{126}$ En un principio coexistieron el sistema presupuestario de financiamiento, desarrollado por el Che, para el sector industrial y el sistema de autogestión financiera, para el comercio exterior y la agricultura. 
taba evidente que estaban dirigidas, cada vez más, a comprimir el papel del sector privado de la economía en beneficio del sector estatal.

Las leyes de reforma agraria ${ }^{127}$ y reforma urbana ${ }^{128}$ primero, $y$ las grandes nacionalizaciones ${ }^{129}$ de las propiedades norteamericanas, ${ }^{130}$ de las empresas industriales y comerciales, de las fábricas, almacenes e instituciones bancarias, y posteriormente ${ }^{131}$ de todo el sector privado, actividades comerciales, de servicios e industriales, trajeron como consecuencia que la economía cubana tuviera que depender, total y absolutamente, del sector estatal.

La asunción de la ideología marxista-leninista a partir de la declaración del carácter socialista de la Revolución, y las alianzas estratégicas sostenidas con la Unión Soviética fueron determinando que en la economía cubana casi desaparecieran determinadas categorías financieras como los cobros, los pagos, el crédito, los impuestos, y que incluso rebasáramos la clásica concepción de la economía socialista de que la propiedad estatal debía ser sobre los medios fundamentales de producción.

La Ley de Reforma Tributaria de 1959, Ley 447, no evidenciaba el posterior desmontaje que sufrió el sistema tributario, pues ella misma declaraba como dos de sus motivos "lograr que el gravamen sea utilizado, esencialmente, como instrumento y medio destinado a acelerar el desarrollo económico y social de la nación, dirigiendo sus recursos monetarios al establecimiento de nuevas industrias y a diversificar las producciones. En segundo lugar, procurar que el peso de los tributos y la presión fiscal generada por ellos, se

127 La primera Ley de Reforma Agraria se promulgó en Cuba en fecha tan temprana como 17 de mayo de 1959, a la cual le siguió la segunda Ley de Reforma Agraria en 1961, las cuales confiscaron grandes extensiones de tierra.

128 La Ley de Reforma Urbana se promulgó el 14 de octubre de 1960.

129 Amparadas en la Ley 851, del 6 de julio de 1960, se dicta la Resolución 1, del 6 de agosto de 1960 mediante la cual se nacionalizaron las empresas de servicios públicos y los centrales azucareros propiedad de entidades norteamericanas y la Resolución 2, del 17 de septiembre de 1960 que nacionaliza la banca norteamericana.

130 Es importante tener en cuenta, al momento de realizar cualquier análisis histórico de este periodo, el férreo bloqueo económico y financiero que desde el año 1962 le impusiera Los Estados Unidos de América al pueblo cubano.

131 Este proceso es conocido como "ofensiva revolucionaria" y condujo a la intervención de toda forma de propiedad privada incluso hasta los pequeños negocios personales o familiares. 
distribuya y reparta con equidad, en razón de la expresión o manifestación de la capacidad económica demostrada". ${ }^{132}$

La Ley 863 del 17 de agosto de 1960 viene a modificar la normativa anterior, debido, como ella misma expone, a la necesidad de incrementar los ingresos fiscales para garantizar el financiamiento de los programas de desarrollo del país, de ahí el aumento en los tipos impositivos. La Ley 998 del 5 de enero de 1962 tampoco responde abiertamente a una política de supresión del tributo, todo lo contario, al ser la primera ley fiscal después de la promulgación del carácter socialista de la revolución reconoce que constituye un vínculo para nuestro desarrollo económico y un importante factor de la edificación del socialismo. En sus propios por cuantos declara que esta ley constituye una ruptura con el sistema impositivo anterior y en consecuencia rescinde los impuestos provinciales y municipales y le otorga un especial tratamiento a las empresas estatales, creando un supuesto tributo ${ }^{133}$ denominado aporte de las empresas estatales al Presupuesto de la Nación.

Dadas las condiciones económicas imperantes en Cuba en ese momento eran lógicos los postulados de la Ley 998/62, pues para ese entonces casi toda la economía cubana era estatal y se priorizaban los ingresos de las nuevas empresas estatales, además de que se comenzaba a contar con créditos ventajosos que empezaban a facilitarse sobre todo por la Unión Soviética.

En 1967 se aprobó la Ley 1213, del 27 de junio, con la cual se entronizaron:

en Cuba los criterios y teorías desarrolladas por la doctrina socialista del este de Europa contra la tributación en general, y muy especialmente contra la imposición indirecta, que postulaban, esencialmente, el rechazo a la tesis de la imponibilidad tributaria por parte del Estado. Esta teoría socialista propugnó la generación de los fondos públicos a través de la redistribución de las ganancias de las empresas estatales hacia los fines de la satisfacción de las necesidades de la población, renunciando, como principio, al tributo como fuente de recaudación esencial de dichos fondos. ${ }^{134}$

132 Valdés Lobán, Eurípides, La imposición sobre el consumo en Cuba. Valoración crítica y propuesta de reforma, Alicante, Publicaciones Universidad de Alicante, Alicante, 2002, p. 165.

133 Sobre la consideración de los aportes como tributos, véase Valdés Lobán, Eurípides, op. cit., nota al pie 107, p. 206.

134 Valdés Lobán, Eurípides, op. cit., p. 207. 
XV. LA CONSTITUCiÓN SOCIALISTA CUBANA DE 1976 :

\section{LA OMISIÓN DE LO TRIBUTARIO}

Es en estas condiciones que se promulga la Constitución socialista de 1976, por lo que no es de extrañar que, siendo consecuente con la política que se había seguido hasta el momento, la materia tributaria no se haya tenido en cuenta. En ese entonces el tributo no poseía ningún protagonismo en la economía cubana, lo que se mantuvo de esta forma hasta la década del 80 , cuando se intentó revivir la tributación mediante la entrada en vigor del Decreto-Ley 44, del 6 de julio de 1981, disposición que, a fin de cuentas, no vino a sistematizar la dispersa y contradictoria legislación tributaria imperante.

El Decreto-Ley 44/81 deroga la Disposición Final Primera de la Ley $1213 / 67$, mediante la cual se eximía del pago de cualquier impuesto a los organismos y empresas estatales. La entrada en vigor de esta norma se debió a la nueva política de Dirección y Planificación de la Economía que se aprueba en el primer Congreso del Partido Comunista de Cuba celebrado en 1975, por la cual se le atribuyó personalidad jurídica propia a las empresas estatales y en consecuencia se les habilitó como futuros contribuyentes.

A pesar de que en esta década se intentó tomar algunas medidas de orden fiscal, estas fueron totalmente desacertadas, como sostiene Gil Vinseiro:

A manera de ejemplo, el Decreto-Ley 50/1982, que regulaba el sector mixto, estimulaba la inversión extranjera, mientras que los impuestos y tipos impositivos a que se obligaba el resto del sector empresarial privado fueron diseñados en momentos en que, por las exigencias de una economía socialista incipiente, se pretendía desestimular la existencia de la propiedad e inversión privada, tanto nacional como extranjera. En tal sentido, ante hechos económicos relativamente iguales y características similares de los contribuyentes, se observaban cargas fiscales diferentes. ${ }^{135}$

La difícil situación que se produjo en Cuba, después del derrumbe del campo socialista de Europa del este, propició que en 1992 se realizara una gran reforma constitucional, con el fin de adaptar nuestra Carta Magna a las nuevas relaciones políticas, sociales y económicas que se avizoraban. A

135 Gil Vinseiro, Alejandro, "Gastos tributarios: breve análisis de su impacto en el sistema tributario cubano", en http://biblioteca.idict.villaclara.cu/UserFiles/File/CI\%20 Disciplina\%20fiscal/6.pdf. 
pesar de la grave crisis económica que atravesaba el país, en ese momento tampoco se valoró por el Estado cubano la importancia de otorgarle rango constitucional a un sistema tributario que, hasta ese momento, había operado limitadamente y sin el debido fundamento en la carta magna.

Esta fue una época en que se inició un proceso de cierta descentralización económica, donde se admitió la posibilidad de inversión directa a los capitales extranjeros, se permitió el desarrollo de nuevas formas de organización mercantil, se crearon nuevos mercados, hubo ciertos cambios jurídicos en la propiedad y en el régimen de tenencia de la tierra, y poco a poco se fue desarrollando una economía emergente.

A pesar del aparente olvido en la reforma constitucional de $1992,{ }^{136}$ las difíciles condiciones políticas y económicas a las que se enfrentaba el país, agudizadas además por la intensificación del bloqueo impuesto por Estados Unidos, y la apertura de la economía cubana a nuevas relaciones, provocó que el tema tributario fuera reevaluado, por su importancia en la recaudación de fondos públicos para la satisfacción de necesidades sociales; y es así que en 1994, sólo dos años después de la reforma constitucional, se promulga la Ley 73, Ley del Sistema Tributario cubano.

En los primeros días del mes de mayo de 1994 se había celebrado la Primera Sesión Extraordinaria correspondiente a la Cuarta Legislatura de la Asamblea Nacional del Poder Popular, en la cual se había acordado que el gobierno debía adoptar determinadas medidas con el fin de lograr el saneamiento financiero que requería el país para su recuperación económica.

Una de estas nuevas medidas fue precisamente la implementación de un nuevo sistema tributario holista, el que debía responder a las necesidades que enfrentaba el país en ese momento, y debía establecerse de manera gradual y flexible.

Para este sistema tributario era imprescindible lograr un equilibrio de las cuentas fiscales. En necesario destacar que, en 1993, el déficit fiscal representó el 33\% del Producto Interno Bruto. Lograr la suficiencia de ingresos

${ }^{136}$ Sólo se introdujo en el capítulo III "Extranjería”, en su artículo 34 tercer apartado, lo siguiente: Los extranjeros residentes en el territorio de la República se equiparan a los cubanos en la obligación de contribuir a los gastos públicos en la forma y la cuantía que la ley establece. 
era uno de los principales imperativos de esta política, dentro del principio de disciplina fiscal adoptado. ${ }^{137}$

El fundamento legal argumentado para la promulgación, por parte de la Asamblea Nacional del Poder Popular, de la nueva norma tributaria fue el artículo 75 inciso b) de la Constitución, la propia Ley expresa en su "Por tanto: La Asamblea Nacional del Poder Popular, en uso de las atribuciones que le confiere el inciso b) del artículo 75 de la Constitución de la República de Cuba, acuerda dictar la siguiente: Ley 73 Del Sistema Tributario. ${ }^{138}$

La promulgación de todo acto normativo conlleva, ${ }^{139}$ en virtud de principio de constitucionalidad y de jerarquía normativa, el correspondiente fundamento jurídico que habilite a la autoridad actuante, primero a promulgar esa determinada disposición jurídica, dígase ley, decreto-ley, decreto, etcétera, y segundo a pronunciarse sobre la materia de que se trate; pues sólo estos dos preceptos justifican plenamente el nacimiento del nuevo acto.

En este caso el fundamento relacionado con la forma nos ha quedado claro, el artículo 75 inciso b) de la Constitución regula: "Son atribuciones de la Asamblea Nacional del Poder Popular: aprobar, modificar o derogar las leyes y someterlas previamente a la consulta popular cuando lo estime procedente en atención a la índole de la legislación de que se trate".

Evidentemente este artículo está facultando a la Asamblea Nacional para dictar leyes, siendo además el único órgano con potestad para hacerlo, de ahí que la promulgación de la Ley 73, desde el punto de vista formal, está dentro de sus competencias.

Al ser éste el único fundamento jurídico que menciona la Ley 73, desde el punto de vista material, resulta dudosa la facultad de la Asamblea de promulgar una Ley del Sistema Tributario, duda que siembra la propia norma al ser omisa en este sentido.

De hecho, autores cubanos defienden que: "La Ley 73 de 1994 es la expresión superior del Sistema Tributario, es el sistema general en la materia y de obligada referencia para aquellas leyes que establezcan regímenes tri-

137 Administración financiera del Estado cubano, Centro de estudios Contables, Financieros y de Seguros, La Habana, 2005, p. 140.

138 Véase Ley 73, del 4 de agosto de 1994, Ley del Sistema Tributario cubano.

139 La parte expositiva de todo acto normativo, constituye su exposición de motivos, y debe hacer referencia, entre otras cosas, al objeto y finalidad de la norma, así como a las competencias y habilitaciones en cuyo ejercicio se dicta. 
butarios diferenciados"; 140 afirmación que abiertamente está reconociendo a esta Ley como la fuente de mayor jerarquía en materia tributaria.

Por su parte, algunos representantes de la doctrina constitucionalista cubana han tratado de salvar esta omisión argumentando, desde diferentes puntos de vista, la regulación del deber de contribuir en la Constitución cubana y en consecuencia el posible respaldo constitucional de la mencionada Ley 73/94.

Una primera posición basa la presencia en la Constitución cubana del deber de contribuir en el precepto del artículo 34, del capítulo Extranjería, donde se equiparan los extranjeros a los cubanos en cuanto al deber de contribuir.

En principio parece bastante lógica esta afirmación, pues si los extranjeros se están equiparando a los cubanos en su deber de tributar, es porque implícitamente se está reconociendo que los cubanos están obligados a contribuir. Sin embargo, el análisis se complejiza si tenemos en cuenta dos elementos trascendentales: el primero, es que estamos analizando no cualquier precepto, sino un deber constitucional, y el segundo, que este artículo mencionado no se encontraba en la Constitución aprobada por referéndum en 1976, sino que se introdujo con la reforma constitucional de 1992.

Al ser los deberes constitucionales contenido especialmente protegido en la Constitución cubana, la regulación del mencionado artículo sólo nos deja dos caminos: entender que se ha introducido el deber de contribuir a los gastos públicos para todos los cubanos, y en consecuencia asumir que el procedimiento seguido para realizar la reforma no fue el adecuado, teniendo en cuenta que se requería la realización de un referéndum popular, el cual nunca se efectuó; o considerar que resulta totalmente contradictorio equiparar a cubanos y extranjeros en cuanto a un deber constitucionalmente inexistente, y que, por tanto, nuestro sistema tributario no posee el necesario referente constitucional.

Por su parte Prieto Valdés ${ }^{141}$ considera que el artículo $64^{142}$ del capítulo VII: Derechos, deberes y garantías fundamentales, es suficiente fundamento para avalar la constitucionalidad del deber de contribuir en Cuba, pues este debe ser considerado un deber cívico y social, por tanto está incluido

140 Administración financiera del Estado cubano, cit., p. 183.

141 Véase Prieto Valdés, Martha, La reforma constitucional de 1992, inédito.

142 Es deber de cada uno cuidar la propiedad pública y social, acatar la disciplina del trabajo, respetar los derechos de los demás, observar las normas de convivencia socialista y cumplir los deberes cívicos y sociales. 
dentro del conjunto de deberes cívico que debe respetar la ciudadanía. Esta posición tiende a suplir mediante una interpretación extensiva la falta de disposición expresa de nuestro texto, pero al igual que la anterior, limita los sujetos obligados sólo a las personas naturales, y excluye a las personas colectivas, sujetos también de la tributación.

A mi modo de ver, tanto un criterio como el otro, lejos de ser beneficiosos para el sistema tributario cubano, lo que provocan, al tratar de legitimar nuestro sistema tributario actual, es crear otros problemas dentro del ordenamiento jurídico. En principio, desde el punto de vista doctrinal, frenan las propuestas teóricas que en esta materia pudieran hacerse, porque si el problema se resuelve con una simple interpretación, ${ }^{143}$ entonces no se hace necesario reformar nuestra Constitución y por tanto no se necesita desarrollo teórico en ese sentido; y por otra parte, si asumimos que nuestra Constitución si prevé el deber de contribuir, y por los preceptos que se aluden, sólo se limita a las personas naturales, entonces, todas las disposiciones, incluida la Ley del Sistema Tributario cubano, que establecen la tributación también para el caso de las personas jurídicas, estarían sobrepasando el mandato constitucional, sin contar en el primer caso se estaría cuestionando el procedimiento seguido en la reforma constitucional de 1992.

Es por esto que concuerdo plenamente con Valdés Lobán, quien manifiesta que con la reforma constitucional de 1992 "no se introdujo precepto alguno de contenido fiscal, de carácter sustantivo" y en consecuencia "el sistema tributario vigente hoy no está sustentado en una legitimidad de rango constitucional". ${ }^{144}$

A pesar de no regular expresamente contenido alguno de carácter fiscal, la Constitución cubana contiene algunos elementos que, como habíamos visto, inciden directamente en el derecho tributario y especialmente en la protección del contribuyente.

Tal es el caso del principio de igualdad, al cual se le dedica el capítulo VII, artículos del 41 al 44 de la carta magna. La regulación de este principio en el artículo 41 se realiza con carácter general, ${ }^{145}$ aunque ya el artículo 42

143 A nuestro modo de ver la solución se busca en el primer caso por la vía de la integración jurídica y en el segundo por la vía de una interpretación extensiva.

144 Véase Valdés Lobán, Eurípides, op. cit., pp. 271 y 272.

145 El artículo 41 de la Constitución de la República de Cuba expresa: Todos los ciudadanos gozan de iguales derechos y están sujetos a iguales deberes. 
responde a la técnica seguida internacionalmente, al establecer un conjunto de prohibiciones contra determinas desigualdades.

El principio de legalidad también está previsto en nuestro texto, el cual regula en su artículo 10: Todos los órganos del Estado, sus dirigentes, funcionarios y empleados, actúan dentro de los límites de sus respectivas competencias y tienen la obligación de observar estrictamente la legalidad socialista y velar por su respeto en la vida de toda la sociedad". Así mismo el artículo 66 establece: "El cumplimiento estricto de la Constitución y de las leyes es deber inexcusable de todos.

Necesariamente si nos referimos al principio de legalidad y a la ley en Cuba, debemos referirnos también al decreto-ley. La relación jerárquica entre la Ley y el Decreto Ley ha generado en nuestro país un profundo debate, del que han resultado dos posiciones totalmente opuestas.

Álvarez Tabío es muy claro cuando sostiene, refiriéndose al Consejo de Estado, que:

...sus decretos-leyes no tienen igual rango que las leyes de la Asamblea Nacional. Es cierto que, según la disposición 11 de la Ley de Tránsito Constitucional (...), las leyes promulgadas con anterioridad a la constitución de la Asamblea Nacional, pueden ser modificadas o derogadas por el Consejo de Estado entre uno y otro periodo; pero no ocurre así con las leyes aprobadas por la Asamblea Nacional, que solo pueden ser modificadas o derogadas por las leyes posteriores de la propia Asamblea. ${ }^{146}$

Por su parte Vega Vega, tomando como fundamento un Acuerdo de la Asamblea Nacional del Poder Popular de 1979, ${ }^{147}$ argumenta:

...la Asamblea Nacional no puede garantizar la continuidad de la actividad legislativa del Estado. La solución es que funcione otro órgano permanente, elegido del seno de la propia Asamblea Nacional, que la sustituya entre uno y otro periodo de sesiones en su actividad legislativa, mediante la aprobación de decretos leyes, con igual rango que las leyes que aprueba la Asamblea Nacional; y pueden modificar o derogar a éstas, con la única diferencia de

146 Álvarez Tabío, Fernando, Comentarios a la Constitución socialista, La Habana, Pueblo y Educación, 1988, p. 295.

147 El mencionado Acuerdo de manera expresa le atribuye a la ley y al decreto-ley una jerarquía idéntica. 
que el Consejo de Estado debe dar cuenta a la Asamblea de la aprobación de esos decretos leyes y aquella puede revocarlos o modificarlos. ${ }^{148}$

Estamos en presencia de dos interpretaciones distintas de nuestro ordenamiento jurídico, pero no podemos dejar de tener en cuenta que el segundo criterio es el que ha imperado en la práctica legislativa cubana, pues resulta muy común en nuestra realidad jurídica que los decretos-leyes deroguen, en sentido amplio, a las leyes. ${ }^{149}$

Para continuar con el análisis del sistema tributario cubano, y en este caso, de los principios de justicia tributaria, tenemos necesariamente que proseguir el estudio a nivel de ley, pues el deber de todos de contribuir con el gato público viene impuesto en nuestra legislación con rango inferior al constitucional, al establecerse en el artículo 6o. de la Ley 73 que:

148 Vega Vega, Juan, Derecho constitucional revolucionario en Cuba, La Habana, Ciencias Sociales, 1988, p. 257.

149 Este hecho no tiene porqué dar por concluido el debate existente en este caso. Matilla Correa considera que “...desde la perspectiva orgánica, los decretos-leyes son normas jurídicas inferiores a las leyes; pero desde la de sus efectos jurídicos, tienen un rango similar y se equiparan a ellas", para este autor "A través de esa vía [el Acuerdo de 1979 de la Asamblea Nacional] el propio ordenamiento positivo cubano he dejado definitivamente estampada la posición que sigue [idéntica jerarquía para ambas disposiciones], zanjando toda posible diferencia de opiniones en relación con ello". Matilla Correa, Andry, "Comentarios sobre las fuentes del derecho administrativo cubano (excepto el Reglamento)", Temas de derecho administrativo cubano, t. I, La Habana, Félix Varela, 2004 , p. 71. No obstante, creemos que otras posiciones u otras interpretaciones pudieran prevalecer en algún momento, basadas sobre todo en el propio texto constitucional, de indiscutible superior jerarquía que el aludido Acuerdo. De la relación de los incisos b) ch) y r) del artículo 75 de nuestra carta magna se pudiera sostener el criterio de subordinación e inferior jerarquía del decreto-ley con respecto a la ley, y en consecuencia su imposibilidad de modificarla. El inciso b), como habíamos visto, faculta a la Asamblea Nacional para aprobar las leyes, mientras que el inciso r) la faculta para "revocar los decretos-leyes del Consejo de Estado y los decretos o disposiciones del Consejo de Ministros que contradigan la Constitución o las leyes". Desde una interpretación literal del texto de este artículo puede entenderse que todo decreto-ley que contradiga una ley debe ser revocado por la Asamblea Nacional, de ahí que el inciso ch) establezca que la Asamblea está facultada para "revocar en todo o en parte los decretos-leyes que haya dictado el Consejo de Estado". Desde esta interpretación, esta facultad no es discrecional, no se trataría de que la Asamblea ratifique o no lo que disponga un decreto-ley, se trata de que el órgano legislativo deje sin efecto una norma de inferior jerarquía que está contradiciendo o derogando una ley. 
Son sujetos del sistema tributario y quedan obligados a tributar, según lo dispuesto por la presente Ley: a) Las personas naturales y jurídicas de nacionalidad cubana, y b) Las personas naturales o jurídicas extranjeras, en cumplimiento de una obligación tributaria generada en el territorio de la República de Cuba. ${ }^{150}$

Esta ley convierte en potenciales contribuyentes, tanto a personas naturales como a personas jurídicas, ya sean ciudadanos cubanos o extranjeros. ${ }^{151}$ En ese sentido el artículo 11 define a los contribuyentes en su inciso i) y establece que contribuyente será toda "persona natural o jurídica, al que la ley impone la obligación de tributar.

Esta definición parte de considerar que todo el que esté en la obligación de tributar, es decir, de pagar el tributo, es contribuyente, sin embargo otros sujetos pasivos pueden encontrarse en esta situación y no por ello pueden considerarse contribuyentes.

El Decreto Ley 169 del 10 de enero de 1997, De las Normas Generales y de los Procedimientos Tributarios, ${ }^{152}$ fue mucho más explícito que la propia Ley 73, y establece en su artículo 29 que "Todo sujeto pasivo tiene como obligación principal, el pago de la deuda tributaria en la cuantía, condiciones y términos establecidos"; no cayendo en el error de considerar como contribuyentes a todos los obligados tributarios. Es en el artículo 31 donde adecuadamente se define al contribuyente, pues la norma tiene en cuenta que sólo puede ser considerado contribuyente quien realice el hecho imponible. Siguiendo ese criterio dispone el mencionado artículo: "Es contribuyente la persona natural o jurídica a la que la ley le impone la obligación de tributar, derivada de la realización del hecho imponible en determinado tiempo y lugar".

150 Véase Ley 73, del 4 de agosto de 1994, Ley del Sistema Tributario cubano.

151 La Ley 1313 Ley de Extranjería, del 20 de septiembre de 1976, establece en su artículo 1 que "Se consideran extranjeros a los efectos de esta Ley, a quienes no siendo ciudadanos cubanos, acrediten ser ciudadanos de otro Estado mediante un pasaporte vigente o documento equivalente expedido a su nombre".

152 La promulgación en 1997 del Decreto Ley 169 se debió, como mismo lo reconoce su último por cuanto, a la necesidad de codificar todas las nomas relativas al procedimiento tributario, las que se encontraban dispersa en varios cuerpos legales. Sin embargo, aún cuando la intención declarada era regular sólo cuestiones procedimentales, el texto de esta disposición jurídica evidencia la presencia de normas sustantivas, las que incluso entran en franca contradicción con algunos de los preceptos de la Ley 73/94. 
Este análisis evidencia la falta de sistematicidad entre ambas disposiciones, y sobre todo las carencias técnicas que presenta la normativa que lidera y ordena la regulación del sistema tributario cubano.

La propia Ley tributaria expresa ${ }^{153}$ que parte de su objeto es el establecimiento de los principios generales sobre los cuales se sustentará el sistema tributario de la República de Cuba, y en su artículo 3o. explícitamente hace referencia a los principios de generalidad, equidad y capacidad económica. El texto del artículo manifiesta "Los tributos han de establecerse basados en los principios de generalidad y equidad de la carga tributaria, en correspondencia con la capacidad económica de las personas obligadas a satisfacerlos".

Con relación a este artículo es preciso hacer tres observaciones. La primera tiene que ver con la regulación del principio de capacidad económica, pues el texto de la norma expresa que se tendrá en cuenta al momento de establecer el tributo la capacidad económica de todas las personas obligadas; sin embargo, sólo los contribuyentes manifiestan capacidad económica al realizar el hecho imponible, ya que el resto de los sujetos se encuentran en la situación de obligatoriedad por condiciones distintas a la manifestación de capacidad económica.

En cuanto al principio de equidad, aun cuando su regulación no es una innovación de la ley cubana, debemos apuntar que constituye una consecuencia del principio de igualdad, y que por tanto debió ser este el que previera el legislador, por otra parte "si nos atenemos a otra de las razones que justifican la progresividad — la teoría del «sacrificio igual» bajo la hipótesis de utilidad marginal decreciente del dinero-, entonces, el término equidad podría incluir también el de progresividad". ${ }^{154}$

El último aspecto al que queríamos referirnos, en relación con el artículo 3o., es la desatención, como mínimo, de otro principio de justicia material aceptado, doctrinal e internacionalmente, por su gran incidencia en la justicia del sistema tributario: el principio de progresividad y no confiscatoriedad del tributo, el cual en unión de los principios de generalidad y capacidad contributiva cierran el círculo que garantiza una adecuada composición del tributo. La ausencia de este principio se evidencia en la regulación del inciso b) de la disposición final quinta de la Ley, que esta-

153 El artículo 1o. de la Ley 73/94 expresa: Esta Ley tiene por objeto establecer tributos y los principios generales sobre los cuales se sustentará el sistema tributario de la República de Cuba que por la presente se dispone.

154 Valdés Lobán, Eurípides, op. cit., p. 272 
blece que el Ministro de Finanzas y Precios está facultado para establecer las bases imponibles y tipos impositivos en forma progresiva o no, con lo cual se está admitiendo la posibilidad de la presencia, en el sistema tributario cubano, de tributos fijos.

Una mención especial requiere el principio de reserva de ley, pues aún cuando constituye el principio de mayor raigambre histórica, su omisión en la Constitución cubana no puede ser salvada por la normativa tributaria, ya que su eficacia depende precisamente de su rango constitucional.

Partiendo de esta carencia, la Ley 73, lejos de tratar de compensar la omisión constitucional, acentúa aún más la ausencia del principio de reserva de ley, al establecer en su disposición final quinta que:

El Ministro de Finanzas y Precios queda facultado, cuando circunstancias económicas y sociales a su juicio así lo aconsejen, para:

a) conceder exenciones y bonificaciones totales, parciales, permanentes o temporales;

b) establecer las bases imponibles y tipos impositivos en forma progresiva o no;

c) establecer que gastos serán deducibles a los efectos del pago de los diferentes impuestos;

d) las reglas para la valoración y definición de las bases imponibles, y

e) las formas y procedimientos para el cálculo, pago y liquidación de los impuestos.

De esta manera se está delegando en la Administración la configuración plena de todo el sistema tributario, pues el Ministerio de Finanzas y Precios adquiere facultades más que abarcadoras, al poder decidir sobre todos los elementos que intervienen en la configuración de los tributos.

Siguiendo esa misma política la disposición final sexta atribuye también a la administración, esta vez en la figura de su máximo órgano, el Consejo de Ministros, o su Comité Ejecutivo, la facultad de dictar:

cuantas disposiciones reglamentarias sean necesarias, con la finalidad de percibir, administrar, controlar y fiscalizar los tributos dispuestos por esta ley, así como establecer el régimen de contravenciones administrativas y las vías para las reclamaciones que los sujetos afectados establezcan a causa de la aplicación de la presente ley. 
Pérez Inclán defiende la posición protagónica que asume el Ministerio de Finanzas y Precios considerando que esta disposición final quinta constituye una previsión "justificable si atendemos a que tenía lugar una reforma tributaria que convertiría a los tributos en una fuente de ingresos importante para la Hacienda Pública...". ${ }^{155}$

Lo cierto es que estas disposiciones dejan en manos de la administración aspectos tan relevantes para los contribuyentes como son: la cuantificación de los tributos (base imponible, tipo impositivo, exenciones, bonificaciones, gastos deducibles, etcétera) y el régimen de contravenciones administrativas y las vías para establecer sus reclamaciones, lo cual los sitúa en un plano de evidente desventaja frente a la administración tributaria. ${ }^{156}$

Razón tiene Valdés Lobán cuando afirma:

De este modo el legislador vulnera — en detrimento de las garantías y derechos del ciudadano-, sin reparo ni contemplación alguna, el principio de reserva de ley tributaria, conquistado en beneficio y para la protección de los derechos individuales. Decimos esto porque, con esta Disposición (...) se desmarca del principio enunciado no sólo por la omisión de su reconocimiento en su parte dispositiva, sino además, y es lo más importante, por acción, al establecer regulaciones como ésta que quebrantan seriamente su imperio. ${ }^{157}$

Desde otra posición, y nuevamente en evidente enfrentamiento con la Ley 73, el Decreto-Ley 169 ofrece un tratamiento más consecuente con el tema analizado, sin embargo, desafortunadamente, lo único que logra es crear más antinomias en la legislación tributaria cubana.

155 Pérez Inclán, Carlos, op. cit., p. 270.

156 Díaz Legón y García Ruiz siguen el criterio de Pérez Inclán sobre la preeminencia del Ministerio de Finanzas y Precios, pero van todavía más allá al afirmar que la fórmula adoptada es más viable que la reserva de ley para exigir los tributos. En este sentido manifiestan: “...el legislador cubano, urgido de una solución a la situación financiera por la que transitaba el país y a sanear las finanzas internas, se vio obligado — sin restar credibilidad a la necesidad de sistematicidad y coherencia del derecho-, a optar por otra fórmula más viable para la exigibilidad del tributo y, dada la debida correspondencia del derecho con la realidad social, a confiar facultades al Ejecutivo que en otras circunstancias debió reservarse”. Díaz Legón, Orestes y García Ruiz, Joarlen, “¿Reserva de ley tributaria en el ordenamiento jurídico cubano? Notas inconclusas para un debate", Panorama de la ciencia del derecho en Cuba. Estudios en homenaje al profesor Dr. C. Julio Fernández Bulté, Palma, Lleonard Muntaner, 2009, p. 493.

157 Valdés Lobán, Eurípides, op. cit., p. 273. 
El artículo 2o. del mencionado Decreto-Ley establece: "Sólo la ley puede establecer tributos, modificarlos o suprimirlos", regulación que si bien no constituye el reconocimiento del principio de reserva de ley, por lo menos prevé lo que doctrinalmente se reconoce como principio de preferencia de ley. Por su parte el artículo 3o. trata de limitar las amplísimas facultades que la Ley 73 le había asignado al Ministerio de Finanzas y Precios, y establece que: "La ley deberá establecer expresamente los casos en los cuales el Ministro de Finanzas y Precios queda facultado para eximir o bonificar el pago de algún tributo, así como las circunstancias en virtud de las cuales la exención o bonificación autorizada podrá aplicarse".

Sobre esta nueva regulación Mesquida del Cueto comenta:

En atención al principio de legalidad visto como reserva de Ley y preferencia de Ley, se aprecia que no funciona una reserva de Ley en sentido estricto, sino una concepción flexible y sí funciona la preferencia de ley, como reglas de jerarquía normativa y congelación de rango, respecto a los tributos regulados por la Ley 73/94; al menos, éstos no pueden ser derogados o modificados sino por una Ley de similar rango a la Ley $73 / 94 .{ }^{158}$

A pesar de lo positivo de esta interpretación, la práctica normativa tributaria cubana ha demostrado que sigue siendo el Ministerio de Finanzas y Precios, es decir, la Administración Tributaria, quien ejerce la facultad de crear, modificar o derogar tributos. Sirva de ejemplo la promulgación de la Resolución 286, del 7 de octubre de 2010, que se ampara en la mencionada disposición final quinta de la Ley 73, para establecer las Normas relativas al pago de los impuestos sobre ingresos personales, sobre las ventas, sobre los servicios públicos, y para la utilización de la fuerza de trabajo, y las referentes al pago de la contribución a la seguridad social por los trabajadores por cuenta propia; derogando las Resoluciones 20, del 22 de mayo de 1997, 253, del 5 de agosto de 2003, 307, del 15 de octubre de 2003, y 212, del 21 de agosto de 2007, todas del propio Ministerio, que anteriormente regulaban esta materia.

En general a partir de 1994 comenzó paulatinamente a funcionar el nuevo sistema tributario. El éxito en la recaudación implicaba una amplia descentralización de instituciones y actividades, esencialmente en las empresas y

158 Mesquida del Cueto, Raysa M., "Caracterización de la reforma tributaria cubana de 1994”, Apuntes de derecho..., cit., p. 233. 
en el trabajo por cuenta propia, lo que a fin de cuentas no llegó a suceder, porque cada vez más se fue limitando la iniciativa privada.

Durante muchos años el régimen especial destinado a cobrar el impuesto sobre utilidades cuando no se pudieran determinar fehacientemente las utilidades netas obtenidas, el cual establecía que debía tenerse en cuenta los ingresos brutos, no se aplicó, y varias empresas pudieron realizar su actividad sin ser gravadas impositivamente.

Tampoco pudo aplicarse el impuesto sobre ingresos personales sobre el salario de los trabajadores del sector estatal, teniendo en cuenta que no existía proporción entre el costo de la vida y los ingresos obtenidos en ese concepto.

Además de esto se tomaron decisiones políticas sin valorar su costo fiscal, pues la sustitución de vallas y otras formas publicitarias comerciales por vallas de carácter político o de divulgación social, restringió considerablemente los ingresos obtenidos mediante la Tasa por la Radiación de Anuncios y Propaganda Comercial, ya que estas últimas se encuentran exentas de pago.

Tal y como explica Torras:

Los vendedores del mercado agropecuario quedaron prácticamente exentos del pago de tributos fiscales, con el objetivo de evitar un aumento mayor de los precios. En la práctica, los precios se dispararon al alza de todas maneras y la exención se mantuvo. El privilegio de no responsabilidad tributaria del Mercado Agropecuario quedó inalterable hasta hoy. ${ }^{159}$

A pesar de las dificultades y limitaciones es muy importante resaltar la importancia del Sistema Tributario para la economía cubana y los avances logrados por el Ministerio de Finanzas y Precios y la Oficina Nacional de la Administración Tributaria en la recaudación de fondos para la satisfacción de las necesidades sociales.

El 2002 trajo consigo una nueva reforma constitucional, las direcciones nacionales de las organizaciones sociales y de masas, haciendo uso de la iniciativa legislativa prevista en el artículo 88 inciso d de la Constitución, elevaron a la Asamblea Nacional una propuesta de reforma, cuyo proyecto de ley fue aprobado mediante el Acuerdo V-74, del 26 de junio de 2002. ${ }^{160}$

159 Torras, Rogelio, ¿"Avanza el Sistema Impositivo?", Cuba a la Mano, http://cubaalamano.net/sitio/client/article.php?id=5382, 19 de febrero de 2009.

160 Esta reforma constitucional de hecho constituyó una respuesta a las medidas de agresión contra Cuba que adoptó el presidente norteamericano y su pretensión de derro- 
Esta reforma iba encaminada fundamentalmente a ratificar el carácter irrevocable del sistema socialista en Cuba y a declarar ilegal cualquier acto realizado por el Estado cubano en violación de su soberanía, bajo agresión, amenaza o coacción de cualquier país extranjero, de ahí que no se haya previsto ninguna otra modificación, aún cuando hubiera sido necesaria.

A pesar de todas las medidas tomadas durante los años noventa del pasado siglo la economía cubana sigue atravesando una profunda crisis, agudizada aún más por la crisis económica y financiera internacional y por el carácter dependiente, de nuestra economía, de las relaciones económicas externas, todo lo que se evidencia en sus limitaciones para enfrentar el déficit presupuestario, los servicios sociales, y el resto de las actividades que hasta este momento había asumido el Estado.

La difícil situación ha llevado a que se adopten nuevas disposiciones encaminadas a solucionar los principales problemas de nuestra economía. Dentro de las nuevas providencias está el pago de la contribución a la seguridad social por parte de los trabajadores del sector estatal y la apertura a la posibilidad de desarrollo de un sector privado de la economía, o más exactamente la fomentación y perfeccionamiento del trabajo por cuenta propia, que aunque no constituye un elemento novedoso, esta vez debe asumir un mayor protagonismo.

En ese sentido han sido dictadas un conjunto de disposiciones normativas, dentro de las que se encuentran algunos decretos-leyes del Consejo de Estado, relativas al sistema tributario o vinculadas de alguna manera a este.

Tal es el caso de los decretos-leyes $274{ }^{161}$ y $275,{ }^{162}$ del 30 de septiembre de 2010, que aunque no se refieren propiamente a la materia tributaria, sí permiten adecuar a la nueva realidad algunas normativas vigentes, y propician, sobre todo el segundo, una mayor apertura en el sector privado de la economía y en consecuencia un aumento de los contribuyentes, y con esto, de mayores ingresos al presupuesto del Estado.

Por su parte el Decreto-Ley 277 de la misma fecha, modifica al DecretoLey 169/97 De las Normas Generales y de Procedimientos Tributarios, y en su único artículo le otorga facultades a los consejos de administración

car el sistema político cubano y destruir la obra de la Revolución.

161 El Decreto-Ley 274/10 modifica el Decreto-Ley 174/97 De las contravenciones personales de las regulaciones del trabajo por cuenta propia.

162 El Decreto-Ley 275/10 es modificativo del régimen de arrendamiento de viviendas, habitaciones o espacios. 
provinciales y municipales para "incrementar el monto de las cuotas mensuales, que como pagos anticipados, están obligados a abonar los sujetos del Impuesto sobre los Ingresos Personales, las cuotas impositivas de los regímenes simplificados y unificados que establezca, y los tipos impositivos a pagar por los sujetos del Impuesto sobre los Servicios Públicos, en lo concerniente al arrendamiento de viviendas, habitaciones y espacios". ${ }^{163}$ Esta norma aumenta aún más las amplísimas facultades que, en materia tributaria, posee la administración cubana, en franca superioridad con respecto a los contribuyentes.

El Ministerio de Finanzas y Precios, por su parte, también ha promulgado un conjunto de nuevas disposiciones entre las que destacan la mencionada Resolución 286, del 7 de octubre de 2010, y la Resolución 287, de la misma fecha, que se refiere a los sujetos del Impuesto sobre Servicios Públicos.

Bolaño Weiss y Regueiro Ale, refiriéndose a estos cambios, manifiestan:

Un análisis a la tributación de los trabajadores por cuenta propia en los últimos años, puso de manifiesto la necesidad de ampliarla y perfeccionarla, máxime cuando las adecuaciones a la política de empleo en el país potencian este sector como alternativa de trabajo, reglamentando la aplicación del pago de los impuestos establecidos en la Ley Tributaria y el aporte en correspondencia con los ingresos que generan las actividades que realizan estos trabajadores; además de regular el pago de la Contribución al entrar en vigor un Régimen especial de Seguridad Social para los trabajadores por cuenta propia y una simplificación en el pago de los impuestos en actividades menos complejas. ${ }^{164}$

Apreciando estos nuevos cambios resulta fácil percatarse del valor que actualmente se le está dando en Cuba al sistema tributario como vía para la captación de ingresos y para la redistribución de la renta. En documento emitido por el Partido Comunista de Cuba, ${ }^{165}$ del 1o. de noviembre de 2010, con vistas a su próximo VI Congreso, denominado Proyecto de lineamientos de la política económica y social, se plantea que la política fiscal debe estar

163 Gaceta Oficial de la República de Cuba, núm. 011 Ext. Especial, del 1o. de octubre de 2010 , p. 80.

164 Comentarios de Meisi Bolaño Weiss, viceministra de Finanzas y Precios y Vladimir Reguiro Ale, vicejefe de la ONAT, publicados en el periódico Granma Internacional Digital, del 1o. de diciembre de 2010.

165 Según el artículo 5o. de la Constitución cubana el Partido Comunista de Cuba es la fuerza dirigente superior de la sociedad y del Estado. 
dirigida a contribuir con el incremento sostenido de la eficiencia económica y de los ingresos al presupuesto del Estado y que el sistema tributario debe avanzar en progresividad y amplitud.

No obstante esta nueva coyuntura o redespertar de la tributación en Cuba, hasta el momento no ha estado marcada por una política de protección jurídica al contribuyente, y de potenciación de los principios de justicia tributaria. La nueva legislación nada ha introducido en este sentido y el mencionado proyecto de lineamientos, aún cuando establece en uno de sus puntos que "el sistema impositivo estará basado en los principios de la generalidad y la equidad de la carga tributaria [y que], se aplicarán mayores gravámenes a los ingresos más altos, para contribuir a atenuar las desigualdades entre los ciudadanos", no va mucho más allá de lo estipulado por la Ley 73/94. ${ }^{166}$

En resumen, pudiéramos afirmar que luego de una consciente ausencia de un adecuado sistema tributario en la economía cubana, las últimas dos décadas han marcado un cambio trascendental en nuestra política fiscal. Lo que ha llevado a que la falta de legitimidad constitucional de la tributación, si bien no resultaba significativa en un principio, en la actualidad se haya convertido en un elemento de trascendencia y de franca amenaza al principio de constitucionalidad.

\section{A MODO DE CONCLUSIONES}

La Constitución cubana, al haber sido promulgada en 1976, y sobre todo, al refrendar un sistema económico, político, social y jurídico en pleno desarrollo y perfeccionamiento, hacia la construcción del socialismo, necesita mantenerse a la par de las transformaciones económicas ${ }^{167}$ que se avizoran, lo que no siempre se logra por la vía de la interpretación.

De ahí que la realidad cubana actual requiera que como mínimo se realice una nueva reforma constitucional.

Por una parte, pudieran variar las formas de propiedad reconocidas constitucionalmente, sobre todo teniendo en cuenta que la regulación de

166 Como resultado del debate promovido en la Comisión núm. 2 del recientemente celebrado VI Congreso del Partido Comunista de Cuba sólo se modificó este lineamiento para agregar que los tributos debían imponerse teniendo en cuenta las peculiaridades de cada provincia o municipio, lo cual demuestra la falta de cultura tributaria de los militantes delegados al Congreso.

167 O de cualquier otro tipo. 
la propiedad personal impide la contratación de fuerza de trabajo y que las formas de propiedad cooperativa sólo se admiten en el sector agropecuario, mientras que por otra, como hemos venido analizando, se hace necesario la regulación de los elementos o principios básicos de nuestro sistema tributario. ${ }^{168}$

La regulación en nuestro texto constitucional de principios tributarios tiene que partir del reconocimiento del deber de todos de contribuir con los gastos públicos.

Tal y como está estructurada en la actualidad nuestra Constitución, y teniendo en cuenta las críticas que ha recibido el hecho de que algunos derechos no se encuentren regulados en su capítulo VII, Derechos, deberes y garantías fundamentales, lo más lógico sería considerar que la inclusión del deber de contribuir debía efectuarse precisamente en este capítulo. No obstante, no podemos dejar de tener en cuenta dos elementos trascendentales, el primero, es la relevancia del deber de contribuir dentro de los fundamentos económicos de todo Estado, y el segundo, que el deber de contribuir constituye el requisito, a partir y en relación con el cual, se regulan los principios del sistema tributario.

Es por esto que sin entrar a cuestionar las clásicas partes en que se dividen las cartas magnas, ${ }^{169}$ consideramos que el deber de contribuir debía regularse en la parte destinada a los fundamentos económicos, claro está con una redacción clara y precisa, que no deje lugar a dudas sobre su condición de deber constitucional, y con ello de contenido especialmente protegido.

A partir de la regulación del deber de contribuir debe dejarse claridad sobre la figura del contribuyente, estableciendo que es toda persona natural o jurídica, que en virtud del deber de contribuir, y debido a la realización del hecho imponible, se encuentra en la obligación de pagar el tributo.

Ahora bien, la constitucionalización del deber de contribuir y de la figura del contribuyente debe venir acompañada de los principios de justicia tributaria; por lo que debe regularse que la concepción y aplicación de los

168 Muchos otros aspectos pudiera tocar una posible reforma, sin embargo, teniendo en cuenta nuestro objetivo, no nos detendremos a abundar en ellos.

169 El hecho de admitir la presencia en la Constitución de una parte dogmática, no implica aceptar que esta deba estar circunscrita a un capítulo o a un determinado número de artículos, sino que la parte dogmática queda identificada por el contenido, el cual puede estar organizado teniendo en cuenta otros criterios, como puede ser la materia de que se trate. 
tributos debe efectuarse en virtud de los principios de capacidad contributiva, generalidad, y progresividad y no confiscatoriedad del tributo.

El principio de reserva de ley en materia tributaria ${ }^{170}$ debe ser asumido, como principio formal, de forma relativa, al regularse que sólo pueden establecerse por ley dictada por la Asamblea Nacional del Poder Popular, los elementos esenciales del tributo, siendo estos: el hecho imponible, la base imponible, el tipo impositivo, las exenciones y deducciones, y el régimen infracciones y sanciones tributarias.

La regulación de este principio automáticamente le estaría restando prerrogativas a la Administración Tributaria cubana, con lo cual evidentemente se está protegiendo al contribuyente.

Otro principio que necesita ser incorporado a nuestro texto constitucional es el que hace referencia a la justicia en el gasto público, para lo cual deben regularse al menos dos límites materiales esenciales: la asignación equitativa de los recursos públicos y la eficiencia y economía en la programación y ejecución de los gastos públicos.

Otro principio que, aunque no lo hemos tratado por no ser privativo del derecho tributario, no puede quedar sin reconocimiento constitucional es el de tutela judicial efectiva, pero su regulación no debe ceñirse al ámbito de protección del contribuyente, sino que debe concebirse como garantía de todos los derechos subjetivos.

Es por esto que debe incluirse el recurso de amparo, que en materia tributaria, garantizaría el acceso de todos los contribuyentes a los órganos jurisdiccionales; y con el fin de lograr que cada vez más la Constitución pueda ser de aplicación directa, su regulación debe dejar claro ante qué tribunal y sala debe presentarse, sin necesidad de realizar pago previo en el caso de reclamaciones que impliquen la liquidación de un crédito. ${ }^{171}$

\section{BIBLIOGRAFÍA}

\section{Libros y revistas}

ALEXY, Robert, "Sistema jurídico, Principios jurídicos y razón práctica”, Revista Doxa, Madrid, núm. 5, 1988. Álvarez TABío, Fernando, Teoría e historia de la Constitución cubana,

170 Este principio también podría tenerse en cuenta para otras materias.

171 Es decir, desde el mismo texto constitucional quedaría abolida la regla "solve et repete". 
La Habana, Unidad Ligera Humanidades, 1964.

— Comentarios a la Constitución socialista, La Habana, Pueblo y Educación, 1988.

AnTONINI, Luca, Dovere tributario, interesse fiscale e diritti costituzionali, Milán, Giuffrè, 1996.

Arrioja Vizcaíno, Adolfo, Derecho fiscal, México, Themis, 2000.

ATIENZA, Manuel y RUIZ MANERO, Juan, "Sobre principios y reglas", Revista Doxa, Madrid, núm. 10, 1991.

Atienza, Manuel y Ruiz Manero, Juan, "Objeciones de principio. Respuesta a Aleksander Peczenik y Luis Prieto Sanchís", Revista Doxa, Madird, núm. 12, 1992.

BIDART CAMPOS, Germán J., "Panorama de los derechos humanos a fin de siglo", La ciencia del derecho durante el siglo XX, México, UNAM, Instituto de Investigaciones Jurídicas, 2011.

Blumenstein, Ernest, Sistema di diritto delle imposte, trad. italiana de FORTE, Francesco, Milán, Giuffré, 1954.

BONEll Colmenero, Ramón, "Principio de igualdad y deber de contribuir", Anuario Jurídico y Económico Escurialense, núm. 38, 2005.

BÜHLER, Lehrbuch Jes Steuerrecht, Berlín, Vahlen, 1927.

BULIT GoÑI, Enrique, "Disquisiciones en torno del Estatuto de derechos y garantías del Contribuyente en Europa y América Latina", Estudios en memoria de Ramón Valdés Costa, Montevideo, Fundación de Cultura Universitaria, 1999, t. I.

Calvo OrTega, Rafael, "Hacia un nuevo derecho tributario", Quito, Revista Foro, Nueva Época, núm. 0, 2004.

- Curso de derecho financiero I, Derecho tributario, Parte general, Barcelona, Civitas, 2008.

CARBOne, Carmelo, I doveri pubblici individuali nella Costituzione, Milán, Giuffrè, 1968.

CARBONELl, Miguel (comp.), El principio constitucional de igualdad, México, Comisión Nacional de los Derechos Humanos, 2003.

CARbonell Cortina, Néstor, El espíritu de la Constitución de 1940, Madrid, Playor, 1974.

CAstro CID, Benito de, Manual de teoría del derecho, Madrid, Universitas, 2004.

CÉSPEDES, Carlos Manuel de, "Aproximación a la Constitución de 1940", Encuentro de la cultura cubana, Madrid, núm. 24, 2002.

Administración financiera del Estado cubano, La Habana, Centro de Estu- 
dios Contables, Financieros y de Seguros, 2005.

Comentarios a la Constitución Española de 1978, Madrid, VLex, 2006.

CORTÉS, Matías, "El equilibrio constitucional y el equilibrio jurídico tributario", Derecho financiero constitucional. Estudios en memoria del profesor Jaime García Añoveros, Madrid, Civitas, 2001.

Cutié Mustelier, Danelia, El sistema de garantías de los derechos humanos en Cuba, Santiago de Cuba, 2001, tesis doctoral, inédito.

Asís RoIG, Rafael de, Deberes y obligaciones en la Constitución, Madrid, CEC, 1991.

Delgadillo, Luis Humberto, Principios de derecho tributario, México, Limusa, 2007.

DÍAZ LEGÓN, Orestes y GARCÍA RUIZ, Joarlen, “¿Reserva de ley tributaria en el ordenamiento jurídico cubano? Notas inconclusas para un debate", Panorama de la ciencia del derecho en Cuba. Estudios en homenaje al profesor Dr. C. Julio Fernández Bulté, Palma (Mallorca), Lleonard Muntaner, 2009.

Domínguez de Oliveira, José Marcos, Capacidade Contributiva. Conteúdo e Eficacia do principio, Río de Janeiro, Renovar, 1988.

DURÁN ROJO, Luis Alberto, "La noción del deber constitucional de contribuir: un estudio introductorio", en http://blog.pucp.edu.pe/item/11527/ sobre-la-nocion-del-deber-constitucional-de-contribuir.

ESSER, J., Principio y norma en la elaboración jurisprudencial del derecho privado, Barcelona, Bosch, 1961.

FANTOZZI, Augusto, La solidarietá nel diritto tributario, Turín, Fantozi, Utet, 1968.

Fauré, Chistine, Las Declaraciones de los Derechos del Hombre de 1789, México, Fondo de Cultura Económica, 1995.

FEDELE, Andrea, "A propósito de una recenté racolta di saggi sul «Porcedimento amministrativo tributario»", Rivista di Diritto Finanziario e Scienza delle Finanze, t. 28, 1971.

FERNÁNDEZ Bulté, Julio, Teoría del derecho, La Habana, Félix Varela, 2002.

FERREIRo LAPATZA, José Juan, Curso de derecho financiero español, Madrid, Marcial Pons, 1994.

FIGUEROA VALDÉS, Juan Eduardo, Las garantías constitucionales del contribuyente en la Constitución Política de 1980, Editorial Jurídica de Chile, 1985.

FIX-ZAMUDIO, Héctor, "Breves reflexiones sobre la naturaleza, estructura y funciones de los organismos jurisdiccionales especializados en 
la resolución de procesos constitucionales", en VEGA GÓMEZ, Juan y Corzo SosA, Edgar (coords.), Tribunales y justicia constitucional. Memoria del VII Congreso iberoamericano de Derecho Constitucional, México, UNAM, Instituto de Investigaciones Jurídicas, 2002.

Flores Zavala, Ernesto, Finanzas públicas mexicanas, México, Porrúa, México, 1995.

FreiXes SANJUAN, Teresa y REMOtTI CARBOnel, Jose Carlos, "Los valores y principios en la interpretación constitucional", Revista Española de Derecho Constitucional, Madrid, año 12, núm. 35, 1992.

GAMBA VALEGA, César, Regímenes especiales del IGVy principios tributarios, en www.ipdt.org/editor/docs/Gamba13-07-05.pdf.

García Belsunce, Horacio A., Temas de derecho tributario, Buenos Aires, Abeledo-Perrot.

García Bueno, Marco César y Ríos Granados, Gabriela, "Alcance de los principios materiales de justicia tributaria en el sistema tributario mexicano: la capacidad contributiva, la igualdad y la proporcionalidad tributaria", Estudios en homenaje a Héctor Fix-Zamudio, Biblioteca Jurídica Virtual, www.juridicas.unam.mx.

García CANales, M., "Principios generales y principios constitucionales", Revista de Estudios Políticos (Nueva Época), núm. 64, 1989.

GARCÍA DE ENTERríA, Eduardo y FERnÁndeZ RodrígueZ, Tomás Ramón, Curso de derecho administrativo, 5a. ed., Madrid, Civitas, 1991.

GARCía VIZCAÍnO, Catarina, Derecho tributario: consideraciones económicas y jurídicas, Buenos Aires, Depalma, 1999, t. I.

GiAnNini, Achille. Donato, Il rapporto giuridico d'imposta, Milán, Giuffrè, 1937.

Giannini, Massimo Severo, Lezioni di diritto amministrativo, Milán, Giuffrè, 1950, vol. I.

GIARDINA, Emilio, Le basi teoriche del principio della capacita contributiva, Milán, Giuffré, 1961.

GIL VINSEIRO, Alejandro, "Gastos tributarios: breve análisis de su impacto en el sistema tributario cubano", en http://biblioteca.idict.villaclara.cu/ UserFiles/File/CI\%20Disciplina\%20fiscal/6.pdf.

González García, Eusebio, "La revisión de la relación jurídica tributaria obligacional: las corrientes procedimentalistas", Foro, Revista de Derecho, Quito, núm. 9, 2008.

GONZÁLEZ PÉREZ, Jesús, El derecho a la tutela jurisdiccional, Madrid, Civitas, 2001. 
HENSEL, Albert, Steuerrecht, trad. italiana de Dino Jarach, Diritto tributario, Milán, Giuffré, 1956.

JARACH, Dino, El hecho imponible, Teoría general del derecho tributario sustantivo, 3a. ed., Buenos Aires, Abeledo Perrot, 1982.

LARA BERRíos, Bernardo, "Derechos y garantías de los contribuyentes en Chile", Revista del Centro de Servicio de Impuestos Internos, 2002.

LeZCANo y Mazón, Andrés M., Las Constituciones de Cuba, Madrid, Cultura Hispánica, 1952.

Micheli, Gian Antonio, Lezioni di diritto tributario, Roma, Bolzano, 1968.

- "Premesse per una teoria della potestá di imposizione", Rivista Diritto Finanziere, Sc. Fin, I, 1967.

MAFFEZZONI, Federico, Il procedimento di imposizione nell'imposta generale sull'entrata, Nápoles, Morano, 1965.

MATILla CORREA, Andry, "Comentarios sobre las fuentes del derecho administrativo cubano (excepto el Reglamento)", Temas de derecho administrativo cubano, La Habana, Félix Varela, 2004, t. I.

MARTín Delgado, Jaime, "Los principios de capacidad económica e igualdad en la Constitución Española de 1978", Hacienda Pública Española, Madrid, núm. 60, 1979.

Martín Queralt, Juan; LozAno SERrano, Carmelo; CASAdo Ollero, Gabriel y TEJERIZO LÓPEZ, José Manuel, Curso de derecho financiero y tributario, La Habana, Félix Varela, 2006.

Martín Queralt, Juan, Lozano Serrano, Carmelo, Poveda Blanco, Francisco, Derecho tributario, 13a. ed., Navarra, Thomson Arazandi, 2008.

MASSONe PARodi, Pedro, Principios de derecho tributario, Valparaíso, EDEVAL, 1979.

MAYER, Otto, Derecho administrativo alemán, El poder tributario, Buenos Aires, Depalma, 1950, t. II.

Menocal y Barreras, Juan M., Derecho fiscal. Constitución, legislación y jurisprudencia cubanas, La Habana, Minerva, 1958.

MESQUiDA DEL CUETO, Raysa, "Disposiciones constitucionales de interés sobre materia fiscal", Apuntes de derecho financiero cubano, La Habana, Félix Varela, 2007.

Molina, René: Reflexiones sobre una visión constitucional del proceso, y sus tendencias jurisprudenciales: hacia un gobierno judicial, Ediciones Paredes, Caracas, 2002. 
MoschetTI, Francesco, El principio de capacidad contributiva, Madrid, Instituto de Estudios Fiscales, 1980.

MOSQUETTI, Francesco y TOSI, Luis, "La capacita contributiva", en AMATUCCI, Andrea (dir.), Trattato di diritto tributario, t. II, vol. I, Padua, Cedam, 1994. NAWIASKY, Hans, Steurrechtliche Grundfragen, trad. al español de Juan Ramallo Massanet, Cuestiones fundamentales de derecho tributario, Madrid, Instituto de Estudios Fiscales, 1982.

Orta, Salvador, Finanzas, Buenos Aires, Guillermo Kraft, 1948, t. I.

PAUNER CHUlVI, Cristina, El deber constitucional de contribuir a los gastos públicos, tesis doctoral publicada por la Facultad de Ciencias Jurídicas y Económicas, Universitat Jaume I, Valencia, 2000.

PeCES-BARBA MARTíneZ, Gregorio, "Los deberes fundamentales", Revista Doxa, Cuadernos de Filosofía del Derecho, Madrid, núm. 4, 1987. PeCZENIK, Aleksander, "Los principios jurídicos según Manuel Atienza y Juan Ruiz Manero", Revista Doxa, Madrid, núm. 12, 1992.

PÉREZ DE AYALA, José Luis, "Las cargas públicas: principios constitucionales para su distribución", Hacienda Pública Española, Madrid, núm. 59, 1979. - Los esquemas conceptuales y dogmáticos del derecho tributario en el derecho español, Madrid, Dykinson, 1997.

PÉrez Cubillas, José M., Curso de derecho fiscal, La Habana, Molina y Compañía, 1950, t. I.

PÉREZ InClÁn, Carlos, "Sistema tributario cubano", Apuntes de derecho financiero cubano, La Habana, Félix Varela, 2007.

PÉRez Royo, Fernando, Derecho financiero y tributario. Parte general, Navarra, Arazandi, 2005.

- Curso de derecho constitucional, Madrid, Marcial Pons, 2001.

Perozo, Javier y MontAner, Jessica, "Tutela judicial efectiva en la Constitución de la República Bolivariana de Venezuela", Revista Frónesis, Caracas, vol. 14, núm. 3, diciembre de 2007.

PRIETO SANChís, Luis et al., Lecciones de teoría del derecho, Madrid, McGraw-Hill, 1997.

PRIETO VALDÉS, Martha, La reforma constitucional de 1992, inédito.

RAMs Puentes, Silvia y PÉREZ Singla, Jaime, Lecciones de legislación mercantil, industrial y fiscal, La Habana, Escuela Profesional de Comercio de Marianao, 1957, t. II.

RAWLS, John, Teoría de la justicia, México, Fondo de Cultura Económica, 1978.

RoA, Arsenio, Ensayo de hacienda pública, La Habana, Imprenta y Pape- 
lería de Rambla, Bouza y Ca., 1927.

RoDríGUEz BEREIJO, Álvaro, "El sistema tributario en la Constitución", Revista Española de Derecho Constitucional, Madrid, año 12, núm. 36, septiembre-diciembre de 1992.

_- "Jurisprudencia constitucional y principios de la imposición", Garantías constitucionales del contribuyente, Valencia, Tirant lo Blanc, 1998.

—_ "El deber de contribuir como deber constitucional. Su significado jurídico", Revista Española de Derecho Financiero, Madrid, núm. 125, enero-marzo de 2005.

Rolla, Giancarlo, Derechos fundamentales, Estado democrático y justicia constitucional, México, UNAM, Instituto de Investigaciones Jurídicas, 2002.

Romano, Santi, Frammenti di un dizionario giuridico, Milán, Giuffrè, 1947.

Rubio Llorente, Francisco, "El principio de legalidad", Revista Española de Derecho Constitucional, Madrid, año 13, núm. 39, septiembrediciembre de 1993.

—_ "Los deberes constitucionales", Revista Española de Derecho Constitucional, Madrid, año 21, núm. 62, mayo-agosto de 2001.

SaCCone, Mario Augusto, Manual de derecho tributario, Buenos Aires, La Ley, 2002.

SAINZ DE BujANDA, Fernando, Lecciones de derecho financiero, 9a. ed., Madrid, Artes Gráficas Benzal, 1991.

SÁNCHEZ SERRANO, Luis, Tratado de derecho financiero y tributario constitucional, Madrid, Marcial Pons, 1997, t. I.

SCHNEIDER, Das Abgabengewaltverältnis, Grundzüge eines allgemeinen Teiles, Mohr, Tübingen, 1918.

SPISSO, Rodolfo, Compendio de teoría general del derecho, Barcelona, Ariel, 1993.

—, Derecho constitucional tributario, Buenos Aires, Depalma, 2003.

SuAREZ, Francisco, Tratado de las leyes y de Dios legislador, Madrid, t. II, vol. 3, libro V, 1968.

TORRAS, Rogelio, “¿Avanza el sistema impositivo?”, Cuba a la mano, http://cubaalamano.net/sitio/client/article.php?id=5382, 19 de febrero de 2009.

TORRÉ, Abelardo, Introducción al derecho, Buenos Aires, Abeledo-Perrot, 2003.

UCKMAR, Victor, Principios comunes del derecho constitucional tributa- 
rio, Bogotá, Temis, 2002.

Ugarte, Ángel, Comentarios a la Constitución de Cuba, La Habana, Talleres tipográficos Solana y Compañía, 1918.

VALDÉS COSTA, Ramón, Instituciones de derecho tributario, Buenos Aires, Depalma, 1992.

- Curso de derecho tributario, Buenos Aires, Santa Fe de Bogotá, Madrid, Depalma-Themis-Marcial Pons, 1996.

VALDÉS LOBÁN, Eurípides, La imposición sobre el consumo en Cuba. Valoración crítica y propuesta de reforma, Alicante, Publicaciones Universidad de Alicante, 2002.

VAREla, Félix, Escritos políticos, La Habana, Ciencias Sociales, 1977.

Vega VegA, Juan, Derecho constitucional revolucionario en Cuba, La Habana, Ciencias Sociales, 1988.

VIDAL, Gladys V., "Aspectos fiscales de relevancia en el camino hacia la Constitución Americana", El Derecho, t. 208, año XLII, núm. 11.056, ejemplar de julio de 2004.

Villabella Armengol, Carlos Manuel, Historia constitucional y poder político en Cuba, Camagüey, Ácana, 2009.

Villegas, Héctor, Curso de finanzas. Derecho financiero y tributario, Buenos Aires, Depalma, 2001.

Zavala OrTiZ, José Luis, Manual de derecho tributario, Santiago de Chile, ConoSur Ltda., 1998.

Zornoza Pérez, Juan J., "El equitativo reparto del gasto público y los derechos económicos y sociales", Hacienda Pública Española, Madrid, núm. 113, 1988.

\section{Legislación}

Constitución de Cádiz, http://www.cervantesvirtual.com/portal/Constitu ciones/españolas/Cádiz1812.

Constitución de la República de Cuba promulgada el 24 de febrero de 1976.

Ley 73, del 4 de agosto de 1994, Ley del Sistema Tributario cubano.

Ley 1313, del 20 de septiembre de 1976, Ley de Extranjería.

El Decreto Ley 169, del 10 de enero de 1997, De las Normas Generales y de los Procedimientos Tributarios.

Decreto-Ley 274/10, del 30 de septiembre de 2010.

Decreto-Ley 275/10, del 30 de septiembre de 2010. 